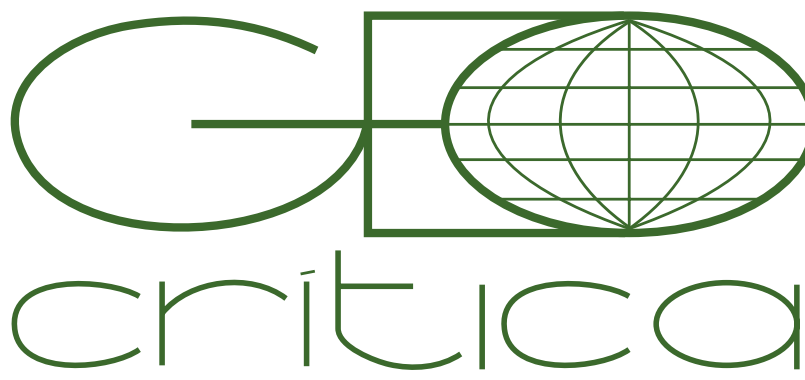

Scripta Nova

Revista Electrónica de Geografía y Ciencias Sociales Universitat de Barcelona

15 de octubre de 2018

\title{
ESCENARIOS DE LA MEMORIA Y EL PODER. LA CONSTRUCCIÓN DEL PAISAJE DE EL VALLE DE LOS CAÍDOS
}

\author{
Gonzalo Madrazo García de Lomana \\ Departamento de Geografía, Universidad Complutense de Madrid \\ gmadrazo@ghis.ucm.es \\ Ester Sáez Pombo \\ Departamento de Geografía, Universidad Autónoma de Madrid \\ ester.saez@uam.es
}

recibido: 20/04/2018 devuelto para correcciones: 02/07/2018 aceptado: 15/09/2018

\section{Escenarios de la memoria y el poder. La construcción del paisaje de EI Valle de Los Caídos (Resumen)}

Este trabajo se centra en tres aspectos relacionados con la construcción del paisaje en el Valle de los Caídos. Analiza el monumento en tanto que símbolo, en comparación con otros ejemplos nacionales e internacionales, atendiendo a la intencionalidad y a la memoria o desmemoria que muestra y esconde su diseño, así como a la incidencia que su uso a lo largo del tiempo ha tenido en su percepción. En segundo lugar, se atiende a las retóricas, en lo que hace a la elección del lugar y a los significados políticos reflejados en su entorno natural y construido. En tercer lugar, se detalla el proceso de creación de un paisaje alrededor del monumento, es decir la repoblación forestal de la finca de Cuelgamuros. Éste proceso de reforestación se contextualiza con las nociones de paisaje que se introducen en el discurso y las actuaciones de los ingenieros de montes durante esas décadas.

Palabras clave: Paisaje, Repoblación forestal, Valle de los Caídos, Memoria, identidad.

Scenarios of memory and power. Landscape construction at the 'Valle de los Caídos' (Abstract)

This paper is centred on three aspects regarding the construction of the landscape at the 'Valle de los Caídos'. To begin with, the monument is analysed as a symbol, drawing a comparison with other examples within Spain and abroad, focusing on its intentionality and the memory or its obliteration shown or concealed there, as well as the impact of its use over time on how it is perceived. Secondly, the rhetoric employed is examined to ascertain how the choice of location and the political meanings reflected in the surroundings are natural or construed. Thirdly, a detailed account is given of the process of creating a landscape around this monument, that is, the reforestation of the Cuelgamuros estate. This forest recovery process is contextualised with regard to the ideas about landscape that were part of the forestry engineers discourse. during these decades

Key words: Landscape, reforestation, Valle de los Caídos, memory, identity. 
¿Cuál es el mayor impacto que han sufrido los paisajes de la Sierra de Guadarrama en el último siglo? Desde la geografía, se podría aludir a la urbanización como proceso genérico que ha afectado a distintos ámbitos del piedemonte, las faldas o los altos puertos y cumbres serranas. No faltan ejemplos de los resultados de este proceso: las grandes infraestructuras ferroviarias y viarias que han acercado la Sierra a Madrid, los ensanches de los pueblos serranos, primero modestos y ahora enormes, las urbanizaciones aisladas, construidas sobre la matriz de grandes propiedades 0 como simples procesos de parcelación del suelo rústico o las construcciones más visibles, que ocupan los altos puertos: residencias, chalés de diversa entidad, sanatorios, pistas de esquí con todas sus infraestructuras etc. ${ }^{1}$. En la enumeración de los cambios territoriales la mayoría de las veces se pasan por alto artefactos concretos especialmente impactantes en el paisaje, entre los que destaca, sobre todos, el Valle de los Caídos como la mayor mácula del piedemonte central y occidental de la vertiente madrileña de la Sierra de Guadarrama² (figuras 1 y 2 ).

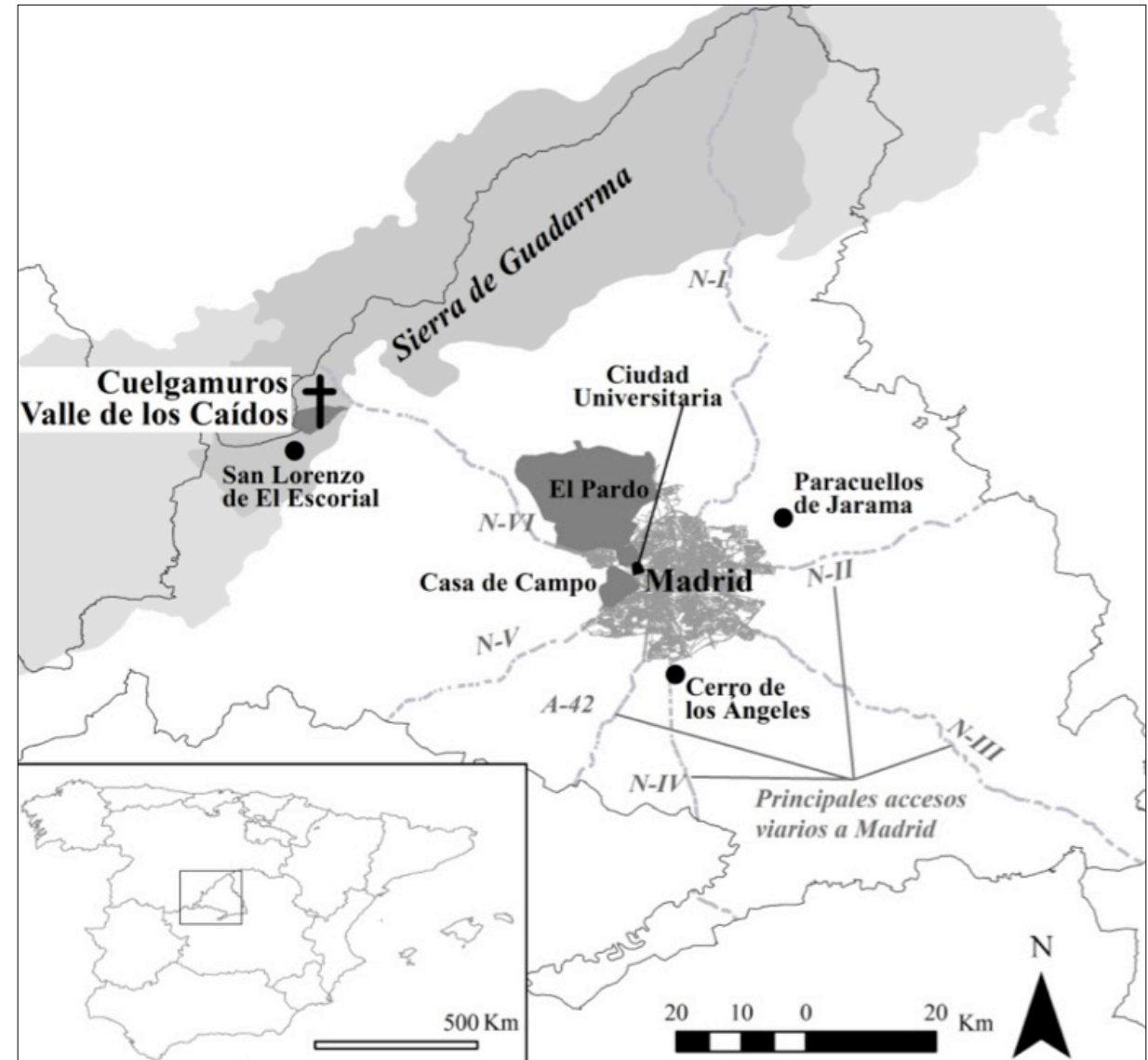

Figura 1. Forestaciones del Patrimonio Forestal del Estado de carácter paisajístico en lugares eminentes del entorno de Madrid.

Fuente: Elaboración propia.

1 La mayoría de los trabajos geográficos sobre las transformaciones territoriales y los cambios en los paisajes de la Sierra de Guadarrama aluden, como es obvio, al proceso de urbanización: Valenzuela Rubio, 1974, 1977, 1992; Mas Hernández, 1998; Sáez Pombo, 2000; Méndez Gutiérrez del Valle, 2008; García Carballo, 2012; Sáez Pombo y Madrazo García de Lomana, 2013.

2 Canosa-Betés, 2016. 


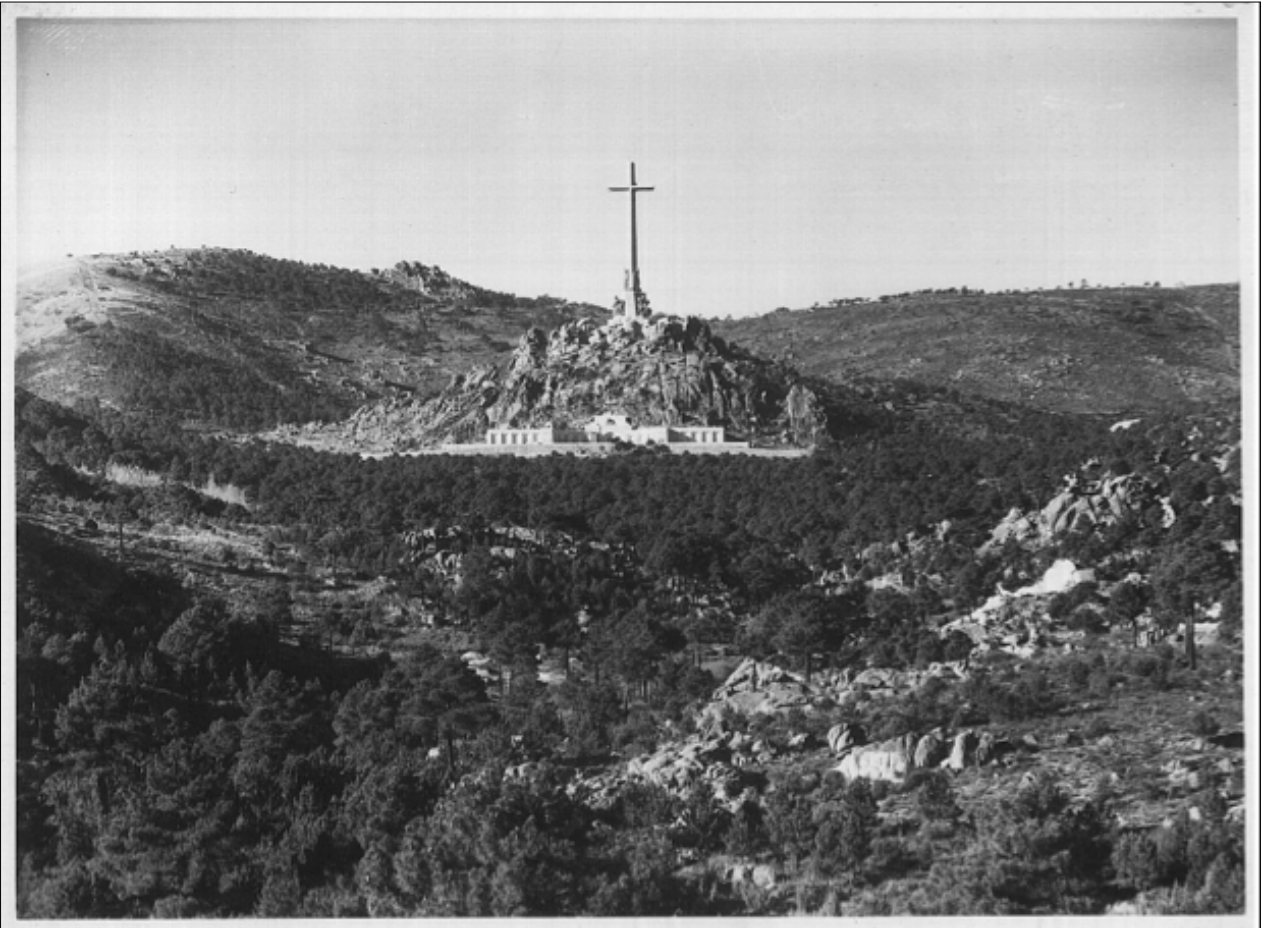

Figura 2. Fotografía de El Valle de Caídos desde la parte baja del monte Cuelgamuros, 1959.

Fuente: AGA, sig. F-00168-19-006.

A pesar de su visibilidad (figura 3) y del debate actual sobre el futuro de este monumento $^{3}$-construido entre 1940 y 1959 tras la Guerra Civil Española (193639)- existe una carencia de trabajos concretos desde la geografía acerca del significado territorial y paisajístico del Valle de los Caídos ${ }^{4}$ : no se ha abordado desde un plano simbólico, relacionado con la construcción de paisajes del poder y como una dimensión geográfica de la memoria ${ }^{5}$, ni desde la perspectiva de su origen patrimonial, de la construcción concreta de su paisaje, del significado e impacto territorial y de su gestión actual. Más allá de la ausencia de la geografía ${ }^{6}$, desde otros campos sí que existe una amplia bibliografía sobre la historia y significado del Valle de los Caídos ${ }^{7}$, sobre su valor artístico ${ }^{8}$ o acerca de su gestión actual y de su futuro9.

3 Este texto se terminó de escribir en julio de 2018 cuando el gobierno se plantea la exhumación del cadáver de Francisco Franco y su salida de la Basílica del Valle de los Caídos; en paralelo prosigue el debate intenso acerca del futuro de este monumento.

4 Esto no quiere decir que no abunden buenos trabajos en España sobre el significado territorial de los memoriales, monumentos y, sobre todo sobre los paisajes en relación con la identidad y la memoria pública. Entre otros muchos: Tort i Donada, 2003 y 2007; Ortega Cantero, 2005 y 2007; Nogué i Font, 2005 y 2016; Ortega Cantero \& García Álvarez, 2009.

5 Johnson, 1995; Osborne, 1998; Foote \& Azaryahu, 2007; García Álvarez, 2009 y 2013.

6 Entre lo poco encontrado desde la geografía sobre Cuelgamuros resulta recomendable

"Topografía del terror de Berlín y las formas de manejar la memoria histórica" en http:// josefinagomezmendoza.com/

7 Aguilar Fernández, 1993 y 1996; Box Varela, 2008; Stockey, 2013.

8 Cirici, 1977, p. 112-120; Bonet Correa, 1981.

9 Ministerio de la Presidencia, 2011; Ferrándiz, 2011; Rueda Laffond y Moreno Garrido, 2013;

Stockey, 2013; Hepworth, 2014. 
Lo que rodea al Valle de los Caídos, tanto en sentido literal sirviéndole de marco paisajístico, como en relación a lo que representa, es un tema incómodo y, desde luego, con implicaciones claras en la cuestión de su futuro. Es, además, un buen ejemplo de la máxima geográfica que denuncia la facilidad de intervenir en el territorio, incluso en casos tan descabellados y costosos como éste, y lo difícil que es borrar o gestionar las huellas físicas y espirituales de estas intervenciones. Una reflexión que se debería tener en cuenta en las obligadas propuestas de futuro, pertinentes a nivel territorial y paisajístico.

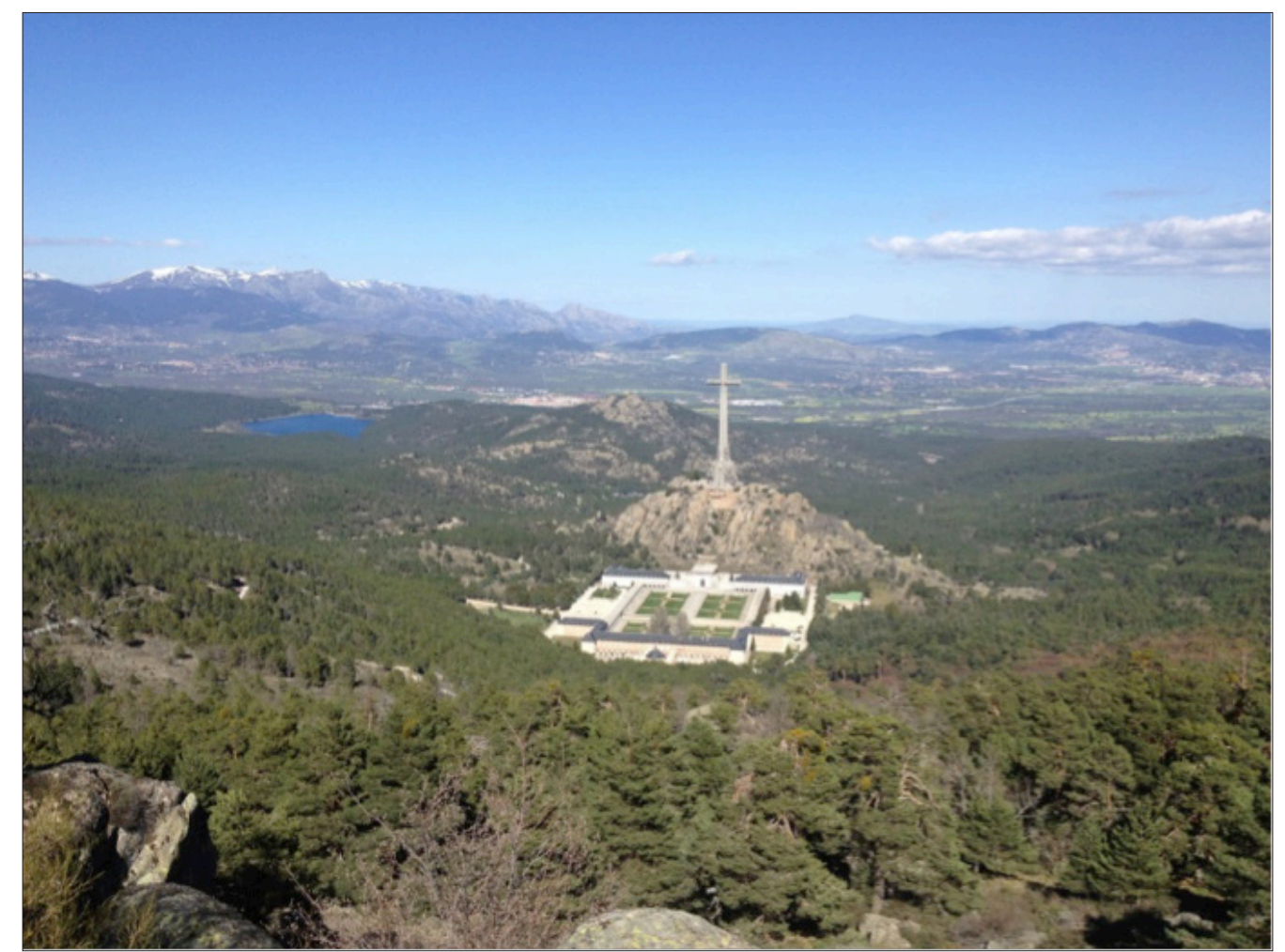

Figura 3. El monte Cuelgamuros, desde la cumbre la sierra, al oeste del monumento, permite apreciar la visibilidad e impacto del Valle de Caídos.

Fuente: G.Madrazo

De ahí deriva el doble objetivo de este artículo: reflexionar primero sobre las aproximaciones teóricas acerca del simbolismo y los discursos sobre el significado paisajístico del monumento y abordar luego el proceso de reforestación, es decir la creación de un escenario para el monumento.

Por ello, la primera parte se va a organizar alrededor de dos cuestiones: en primer lugar, se revisarán algunos enfoques que abordan el diseño y el valor simbólico de esos espacios significativos para el poder en otros países, particularmente aquellos promovidos por dictaduras o regímenes totalitarios. En segundo lugar se abordará la retórica del franquismo sobre el Valle de los Caídos, tanto en lo que hace a la elección del lugar, como a los significados políticos que se otorga a los conceptos naturaleza y paisaje, empleados habitualmente y de forma intencionada por el régimen. 
En la segunda parte, la atención se centra - a partir de la documentación original del proyecto y de los textos coetáneos a su ejecución- en el análisis riguroso y crítico de la repoblación alrededor del monumento y del discurso que acompaña a ésta intervención, atendiendo a su justificación, objetivos e implicaciones en el contexto del franquismo.

\section{Geografía y monumentos. Símbolos, poder y lugares de la memoria pública}

Para desentrañar el significado territorial del Valle de los Caídos es pertinente buscar paralelismos con otros trabajos que desde la geografía u otras disciplinas afines se han realizado sobre monumentos, memoriales, cementerios y otros lugares asociados a la memoria de las sociedades. A pesar de la dispersión de las perspectivas investigadoras sobre tales cuestiones, así como del alejamiento de algunas de ellas para un trabajo de geografía, resulta a nuestro juicio necesario su repaso. Se intenta con ello responder a qué tipo de memorial es, su simbología y significado, y, lo que es más relevante, valorar si los cambios acecidos desde que se erigió el monumento han modificado su sentido original.

\section{Tipos de memoriales. Programa simbólico y retórica en torno al Valle de los Caí- dos}

El Valle de los Caídos es la herencia más significativa del franquismo: aúna visibilidad ineludible y simbolismo sobresaliente. El monumento se levantó entre 1940 y $1959^{10}$, no como un memorial modesto de los muchos que erigieron los vencedores para conmemorar a los caídos por "la cruzada"11, sino que en el Valle de los Caídos se quiso compaginar la grandeza monumental para el recuerdo de los caídos y de la victoria, con su conversión en un lugar de peregrinación, como deja claro el decreto que promueve la obra ${ }^{12}$ y otros folletos laudatorios sobre su origen ${ }^{13}$.

El Valle de los Caídos leído en clave territorial es sin duda un espacio que refleja el poder y una lectura determinada de la historia. Se identifica con lo que algunos han denominado símbolos del poder, lugares de memoria ${ }^{14}$, dimensión territorial de la memoria pública ${ }^{15}$, paisajes del poder ${ }^{16} 0$ marcas territoriales ${ }^{17}$. Todas estas expresiones traducen, además, la voluntad de relacionar tales lugares con la identi-

10 Entre los abundantes estudios dedicados a la historia del Valle de los Caídos a nuestro juicio destacan trabajos rigurosos, como los de Sueiro, 1976; Aguilar Fernández, 1996 o Box Varela, 2008. 11 Box Varela, 2008, p. 176-183.

12 Decreto 1 de abril de 1940, “disponiendo se alcen basílica, monasterio y cuartel de juventudes en la finca situada en las vertientes de la Sierra de Guadarrama (El Escorial), conocida por Cuelgamuros, para perpetuar la memoria de los caídos en nuestra gloriosa Cruzada".

13 Pérez de Urbiel, 1959; Méndez, 1982.

14 Nora, 1984 (reed. 1997).

15 Foote \& Azaryahu, 2007; Forest, Johnson \& Till, 2004.

16 Osborne, 1998.

17 Jelin \& Langland, 2003. 
dad nacional ${ }^{18}$. Y con todas estas denominaciones se puede identificar el Valle de los Caídos, aún con los matices que introducen los distintos autores, porque frente a otras "marcas territoriales" individuales - monumentos, estatuas, cementerios, panteones, lugares sagrados o cambios en la toponimia - en Cuelgamuros se levantó un conjunto que engloba todo tipo de elementos simbólicos: hay gran profusión de estatuas y otras formas artísticas y un gran monumento en forma de cruz; un cementerio que acoge los restos de cerca de 34.000 víctimas de la guerra ${ }^{19} \mathrm{y}$ un panteón en el que se custodia y honran los huesos y la memoria de Franco y José Antonio; pero es también una basílica que forma parte de una abadía (benedictina) e, incluso, el topónimo vernáculo, Cuelgamuros, ha sido sustituido por otro: el Valle de los Caídos. En definitiva, más que una marca, un elemento, una construcción en singular, el valle de los Caídos es sobre todo un proyecto monumental y territorial.

Algunos autores han propuesto tipologías para comprender las diferencias e intencionalidad de los monumentos conmemorativos de estos conjuntos, destacando sobre todos la aplicación de la noción "lugar de memoria"20, definido por Pierre Nora como un conjunto conformado por una realidad histórica y otra simbólica: un personaje, un lugar, un hecho, un símbolo...21. Dentro de la amplitud del concepto, aplicado para toda Francia en la obra Les Lieux de mémoire, en el capítulo dedicado a los monumentos a los muertos, se ofrece una tipificación interesante en categorías no excluyentes: monumentos cívicos, patrióticos, a la victoria, funerarios y/o pacifistas ${ }^{22}$. En el caso del Valle de los Caídos esta clasificación se solapa, pues se suman motivos patrióticos, victoriosos y funerarios, mostrando en cualquier caso la intencionalidad en la erección del memorial. No faltan otras clasificaciones del papel de los memoriales de guerra en el paisaje, como la interesante propuesta de James M. Mayo, dentro de la que el Valle de los Caídos se encontraría en la cúspide de la tipificación, como un sitio ritual, donde el Estado persigue sacralizar el lugar y destinarlo a ceremonias públicas ${ }^{23}$.

Entrando ahora en la simbología en torno al Valle de los Caídos, el análisis de los programas escultóricos de los monumentos, de su significado y la retórica que les rodea, así como del uso que tienen forma parte de casi todos los trabajos que desde la Geografía política y cultural, desde la historia o desde otras disciplinas (Historia del Arte o Antropología) se han aproximado a su estudio espacial.

18 García Álvarez, 2009.

19 Ministerio de la Presidencia, 2011, p. 10-11.

20 García Álvarez, 2009, p. 179-184 expone con nitidez la relaciones del concepto lugar de la memoria con la geografía (de la memoria).

21 Nora, 1984 (Reed. 1997) y 1989.

22 Prost, 1984, p. 199-223

23 Mayo, 1988, p. 68. Hay gran profusión de clasificaciones de la estatuaria monumental de carácter histórico-artístico; ciñéndonos a Madrid valga Fernández Delgado, 1982 y a nivel institucional el catálogo de BIC's o http://monumentamadrid.es. No obstante, estas clasificaciones se centran en los aspectos formales de los monumentos, más que en la intencionalidad y funcionalidad política que aquí nos interesa. 
Comenzando por las investigaciones minuciosas sobre la simbología de los mismos y de su relación con la memoria pública y la identidad colectiva, no faltan desde luego trabajos del Valle de los Caídos y de otros conjuntos monumentales franquistas en Madrid y sus alrededores ${ }^{24}$. Proliferan estudios que con perspectivas acríticas se limitan a describir los elementos que componen el monumento, despojándolos del significado del lugar, a imagen de lo que en definitiva se dice en las guías oficia$\operatorname{les}^{25}$. Nos quedamos con la valoración artística que hace Antonio Bonet Correa al respecto del Valle de los Caídos, para el que la supuesta paternidad mental de Franco y la sucesión de direcciones generaron un conjunto "internamente desconectado" que merece la calificación de kitsch ${ }^{26}$.

Por otra parte los estudios de monumentos concretos se detienen en el análisis del programa simbólico de la estatuaria, valorando la adecuación de los estilos históricos, realistas o naturalistas u otras formas abstractas. Cabe entonces preguntarse si tiene sentido cuestionarse cómo rendir homenaje a lo innombrable, al horror; o son más éticas las posiciones "contramonumento" que consideran que tranquilizando la memoria al sustituirla por un objeto se promueve el olvido público. También resulta interesante cuestionar el papel que juegan en el diseño final las corporaciones que los patrocinan y el sello del autor que los ejecuta ${ }^{27}$.

De mayor interés, en relación con el tema que nos ocupa, es la vinculación del programa simbólico del monumento con su entorno, partiendo de un sentido locacional respecto a lo que quieren conmemorar, pasando por su visibilidad o preeminencia, hasta su relación con el tejido urbano o el contexto territorial en el que se insertan. Estas cuestiones son un motivo de análisis especialmente intenso en los trabajos geográficos ${ }^{28}$. En el caso del Valle de los Caídos, evidentemente la elección del lugar no es azarosa por su visibilidad, paralelismos con El Escorial y el entorno natural -se comentara más adelante- y encaja en "el gusto reaccionario por lo agrario, que se mezcla así con el romántico de la naturaleza salvaje e indomable" que lleva a que "estos monumentos se eleven siempre sobre cerros o colinas, recortando su silueta en el cielo"29.

Es Eric Hobsbawm quien sintetiza con una gran claridad las demandas básicas del poder al arte, que se maximizan con regímenes autoritarios o totalitarios del siglo XX. Se trata de que el arte demuestre y celebre el poder, de que se organice como un drama público y ritual - para lo que son óptimas grandes explanadas-y de hacer

24 Cirici, 1977; Bonet Correa, 1981; Box Varela, 2008.

25 Sirva de ejemplo la Guía oficial de la Santa Cruz de Valle de los Caídos que edita Patrimonio Nacional desde 1959. No nos molestamos en citar otras muchas guías turísticas que hacen una descripción banal del conjunto.

26 Bonet Correa, 1981, p. 326

27 Jelin \& Langland, 2003, p. 3-10.

28 Harvey, 1979; Ignatieff, 1984; Atkinson \& Cosgrove, 1998; Johnson, 1995; Osborne, 1998; Sidorov, 2000; Forest \& Johnson, 2002; Stangl, 2003; Foxall, 2013.

29 Bonet Correa, 1981, p. 319. 
un uso educativo para crear sistemas de valores, como antes realizaba la iglesia y luego asumió el estado decimonónico ${ }^{30}$.

Si lo primero, la relación entre los monumentos y el poder, ha quedado claro y demostrado, la idea del arte como un drama público destinado además con su simbolismo a educar a las sociedades es otra faceta profundamente estudiada, en el caso del Valle de los Caídos por Zira Box, que relata con gran profusión el calendario de celebraciones y las ceremonias desarrolladas en Cuelgamuros ${ }^{31}$. De alguna manera toda esa fanfarria nos remite a la noción de "tradiciones inventadas" que el mismo Hobsbawm desenmascara con nitidez ${ }^{32}$. En el fondo las celebraciones y el programa artístico del monumento no dejan de ser una suma de interpretaciones de la historia, convirtiendo toda esa fachenda en tradiciones inventadas ${ }^{33}$.

Aparte, otro de los argumentos usados para justificar las bondades del monumento desde perspectivas supuestamente objetivadoras ha sido la cifra de visitantes que en el periodo 2012-2016 se ha movido entre los 240.000 y los $263.000^{34}$. Obviamente, este flujo de turistas, ha estado apoyado desde su inauguración por una potentísima publicidad institucional y por su promoción en el marco de las rutas turísticas a otros monumentos, principalmente el Monasterio de San Lorenzo de El Escorial, pero también ciudades monumentales como Ávila, Toledo o Segovia. Las visitas turísticas han tratado de blanquear el monumento, máxime cuando en el caso de las guías en inglés omitían cierta palabras como "cruzada" o interpretaciones de los vencedores o alusiones a los que dieron su vida por España, en favor de enunciados más asépticos, del tipo de todos los caídos por sus ideales o todos los caídos en la guerra ${ }^{35}$.

\section{Cambios en el discurso, el uso y el significado del monumento. Un futuro discuti- do}

La desmesura del proyecto condujo a un enorme retraso en la finalización de su obra, tal y como ocurriera con otras construcciones significativas del franquismo que, en el contexto de la posguerra y el aislamiento, tardaron décadas en acabarse. Así, el Cerro de los Ángeles, iniciado en 1940, no se inaugura hasta 1965 y la iglesia se concluye en 1976; y el Arco de la Victoria en Madrid no se finaliza hasta $1950^{36}$. Esto no es excepcional, pues en otros países monumentos y memoriales colosales

30 Hobsbawm, 1995, p. 11-15.

31 Box Varela, 2008, p. 201-210.

32 Hobsbawm, 1983, p. 1-14.

33 Desde luego el traslado de los restos de José Antonio a El Escorial y desde ahí a Cuelgamuros estuvo rodeado de un simbolismo y liturgia en el que la tradición se reinventa (Hermoso Cuesta, 2017). La fiesta del obispillo y otras liturgias, restablecidas o novedosas son ejemplos de los horizontes históricos y tradicionales en los que se mueve el recinto.

34 Durante mucho tiempo ha sido el tercer monumento más visitado de Patrimonio Nacional por detrás del Palacio Real de Madrid y del Monasterio de El Escorial -entre 1991 y 2005 recibió anualmente cifras que van de los 673.000 y los 392.000 visitantes- siendo superado recientemente por otros recintos. Memorias de Gestión del Patrimonio Nacional.

35 Aguilar Fernández, 1996, p. 125-126; Hite, 2013, p. 56-59.

36 Bonet Correa, 1981; Aguilar Fernández, 1996; Box Varela, 2008. 
tardaron igualmente décadas en concluirse, ya los promovieran democracias liberales o regímenes totalitarios, provocando que el fervor inicial de la obra construida se templara o que el significado original se difuminara ${ }^{37}$.

Así cuando se inauguró el Valle de los Caídos en 1959 (figura 4), y más aun posteriormente, se trató de matizar el sentido del memorial, introduciendo en sus columbarios los restos de combatientes del bando republicano y manejando una retórica en la que se refería la reconciliación ${ }^{38}$. Pues bien, el intento de mutar el significado original de la obra no es tampoco un caso exclusivo, ya que también otros memoriales cuya erección dividió a la sociedad y se tardaron décadas en concluirse, como el Sacré-Coeur de París ${ }^{39}$ o el monumento a Vittorio Emmanuelle II en Roma ${ }^{40}$ conocen los mismos intentos de mutar su significado original; de la misma manera, no faltan ejemplos de la evolución o modificación del sentido oficial de algunos monumentos conmemorativos en el contexto de las dictaduras comunistas del Este de Europa ${ }^{41}$.

Evidentemente la historia (y la geografía) no son inmutables, no se detienen el tiempo y el espacio para contemplar el Valle de los Caídos, como deseaba la retórica inflamada que acompañó el inicio de la construcción. El paso del tiempo pone en su lugar ciertos proyectos, o al menos establece si lo que se proyectó era sostenible. En un sentido meramente físico el conjunto monumental del Valle de los Caídos es insostenible: la cruz está cerrada, las imponentes estatuas de Juan de Ávalos en su base se desmoronan, la basílica subterránea está llena de filtraciones y en los columbarios los restos óseos se encuentran en un estado penoso a causa de la humedad ${ }^{42}$. Problemas cuya responsabilidad recae, primeramente, en el autor intelectual de la obra.

En un sentido simbólico la cosa se complica. Desde luego, dada su localización y naturaleza no le ha ocurrido como a otros monumentos urbanos del franquismo en los que el paso del tiempo, la desmemoria y las nuevas funciones sociales han hecho que se pierda el uso y vocación de recuerdo y memoria con los que inicialmente fueron proyectados. Esto es extensible y ha sido estudiado en multitud de monumentos en el mundo, fundamentalmente desde aportaciones de la antropología y la sociología ${ }^{43}$; pero también desde la geografía, analizando las modificaciones de uso de monumentos y memoriales y su relación con el espacio urbano ${ }^{44}$.

Las transformaciones sociales a veces se acompañan de cambios políticos y de intentos de modificar los monumentos, los memoriales, la toponimia, etc. ya sea con

37 Harvey, 1979; Johnson, 1995; Osborne, 1998; Atkinson, \& Cosgrove, 1998; Stangl, 2003.

38 Aguilar Fernández 1996, p. 125-126; Stockey, 2013, p. 72-85.

39 Harvey, 1979.

40 Atkinson, \& Cosgrove, 1998.

41 Stangl, 2003; Forest \& Johnson, 2002; Forest, Johnson \& Till, 2004.

42 El Informe de la Comisión de Expertos sobre el Futuro del Valle de los Caídos constataba su grave deterioro y la fuerte inversión necesaria para alargar su vida útil. Ministerio de la Presidencia, 2011, p.6.

43 Jelin \& Langland, 2003; Hite, 2013; Sorensen \& Viejo-Rose, 2015.

44 Johnson, 1995; Osborne, 1998; Stangl, 2003; Foote y Azaryahu, 2007. 
la voluntad de ajustar o de reinterpretar el significado de esas obras o, simplemente, para eliminarlos. Evidentemente en periodos de cambio se hacen efectivas con facilidad las transformaciones en la toponimia del callejero urbano. La retirada de estatuas es otra opción muy extendida, particularmente en el Este de Europa ${ }^{45}$, pero ¿qué hacer con ellas? Incluso ciudades como Berlín o Moscú muestran las transformaciones a través de proyectos urbanos que buscan modificar sus paisajes urbanos, localizando referencias históricas que transformen la memoria de la ciudad ${ }^{46}$. Estas mutaciones en los escenarios son evidentes y redundan en "la memoria colectiva" que se transforma a partir de las nuevas imágenes y símbolos que se incorporan en el paisaje ${ }^{47}$.

Con los grandes conjuntos monumentales, como el levantado en Cuelgamuros, las posibilidades son más complejas por las dimensiones del artefacto. Los mensajes para transformar su sentido inicial, primero del Régimen y después de voces neofranquistas, no tienen más recorrido que la simple retórica, pues ninguna propuesta ha previsto o prevé alterar nada del programa arquitectónico, simbólico y, en general, nada que afecte a la integridad del monumento. Por ello es evidente que el Valle de los Caídos, tanto en sus aspectos tangibles como figurados, se encuentra inevitablemente vinculado a una ideología política determinada: desde la formulación y diseño del monumento, pasando por la ejecución de la obra con la participación de presos políticos, la opaca historia de los traslados de restos y su pésima conservación, hasta el debate sobre su uso actual y futuro ${ }^{48}$.

No obstante, la dificultad física - dada la envergadura del conjunto construidoy la susceptibilidad social que todavía despierta este tema no justifican la parálisis política que genera, pues siendo el memorial más significativo heredado del franquismo la indefinición acerca del futuro del conjunto se ha manifestado en el continuismo en su gestión. Solo en los últimos 15 años, de la mano de movimientos civiles, han ganado importancia las reivindicaciones de una política de memoria que 'resignifique' el monumento ${ }^{49}$. En este tiempo se ha aprobado una Ley de Memoria Histórica - que apenas alude al Valle de los Caídos $^{50}-$ y se ha solicitado un informe a una comisión de expertos sobre el futuro del Valle de los Caídos, donde funda-

45 Forest, Johnson \& Till, 2004.

46 Till, 1999; Sidorov, 2000.

47 Para complicar más las cosas, dice Susan Sontag que la memoria colectiva no existe sensu stricto, sino una instrucción colectiva que establece lo ocurrido. Citada por Hite, 2013.

48 Sueiro, 1976; Solé i Barjau, 2009; Ferrandíz, 2011. El último autor sintetiza el abanico de valoraciones sociales actuales respecto del Valle de los Caídos, entre el anacronismo nostálgico de los neofranquistas, pasando por el anacronismo indiferente de quienes no se sienten molestos por su presencia y el anacronismo incómodo de quienes lo rechazan pero no encuentran un anclaje para su relectura, hasta el anacronismo hiriente de aquellos que lo consideran una grave ofensa a los vencidos.

49 Ferrándiz, 2011; Rueda Laffond y Moreno Garrido, 2013.

50 Ley 52/2007, art. 16, dispone que el Valle de los Caídos se regirá estrictamente por las normas aplicables con carácter general a los lugares de culto y a los cementerios públicos y que en ningún lugar del recinto podrán llevarse a cabo actos de naturaleza política ni exaltadores de la Guerra Civil, de sus protagonistas, o del franquismo. 
mentalmente se aboga por la modificación de su significado y la desacralización del conjunto $^{51}$. Sin embargo sus recomendaciones han sido ignoradas hasta hoy, predominando la continuidad, teñida de provisionalidad, en su administración ${ }^{52}$.

\section{La naturaleza, el paisaje y su patrimonialización durante el franquis- mo}

Algunas visiones de la naturaleza y el paisaje del franquismo parecen condensarse en el Valle de los Caídos, lo que se refleja en la elección del lugar de la obra y en su justificación, así como en el estilo de la forestación de su entorno. Por un lado, el Patrimonio Forestal del Estado (PFE) recibió el encargo de repoblar el monte de Cuelgamuros, para lo que aportó sus ideas ambientales y el bagaje técnico de las reforestaciones que ejecutaban por toda España en esas décadas ${ }^{53}$. Concretamente, en relación a la reforestación de Cuelgamuros y de otras zonas de interés político, en 1964 el Boletín informativo del PFE lo expresaba así: “... el Patrimonio Forestal del Estado ha plantado más de dos millones de árboles -en el Valle de los Caídos-, que al sucederse en el tiempo harán patente, ante nuestros sucesores, la presencia de la España forestal en los actos más trascendentes de nuestra Patria"54. Por otro lado, se suma a lo anterior las valoraciones paisajísticas que parten de los discursos franquistas sobre la naturaleza y el paisaje, que guardan parecido - con algunas particularidades - a las realizadas en otros regímenes totalitarios o dictatoriales del siglo XX, por su grandilocuencia, por su exacerbada retórica, que parece convertir los discursos en palabras de charol ${ }^{55}$. Valga como muestra un fragmento de la guía oficial del monumento que agrupa algunos de los calificativos manidos favoritos del franquismo: "Ante los ojos se ofrece un valle bravo y recio, bellísimamente dispuesto. Por todas partes aflora la roca, y solo el pino, la jara, el roble y el chopo (...) se encargan de dar al paisaje la austeridad que reclama la vecina sierra de Guadarrama" ${ }^{\prime \prime 6}$.

En las próximas páginas se abordarán los discursos de tinte político sobre el paisaje de Cuelgamuros, dejando para más adelante las valoraciones técnico-forestales, con el fin de lograr una mayor claridad, a pesar de que ambas retóricas se cruzaban en muchas ocasiones, como demuestran las citas anteriores.

\section{Naturaleza, paisaje e identidad en discurso político de las dictaduras}

Si nos fijamos primero en las soflamas del régimen franquista sobre el paisaje y la naturaleza, una primera aproximación parece demostrar el sentido elevado que se

51 Ministerio de la Presidencia, 2011.

52 La Fundación de la Santa Cruz del Valle de los Caídos, creada por el Decreto Ley de 23 de agosto de 1957, se encuentra administrada por el Consejo de Administración del Patrimonio Nacional mientras no se desarrolle lo previsto en la Disposición final tercera de la Ley 23/1982, de 16 de junio, reguladora del Patrimonio Nacional.

53 Gómez Mendoza, 1992; Gómez Mendoza y Mata Olmo 1992.

54 González Aldama, 1964, p. 33.

55 Sánchez Ferlosio, Rafael. Campo de Retamas. Barcelona: Penguin-Ramdom House. 2015, p. 85. Citado por Ruiz Zapatero, 2016, p. 45.

56 Patrimonio Nacional, 1959. Subrayado autores. 
otorga a esos conceptos. Algo común a otros regímenes dictatoriales del siglo XX, como demuestran numerosos estudios que han atendido a los discursos y políticas de la naturaleza o forestales de Alemania, de Italia, de la Unión Soviética, de otros países del Este de Europa o de Portugal y de España ${ }^{57}$.

Existe una clara tendencia a la sacralización de la naturaleza y del paisaje por los nacionalismos del siglo XIX y XX, que Stephen Brain aquilata en la sentencia: "los dictadores han sido amigos de los árboles", una frase que, no obstante, debe ser matizada para cada país. Es cierto que la naturaleza y, particularmente, los bosques significan para los movimientos naturalistas de algunas naciones el espacio original, prístino, que arraiga sobre un suelo que evoluciona con el pueblo mismo y, por tanto, es el reflejo de sus esencias.

Así, la relación de la identidad con los bosques es algo que se reitera en casos como el de Rusia y Alemania a finales del siglo XIX -abundantemente estudiadosen los que esa relación entre naturaleza e identidad nacional se afirma en clave histórica frente a otros pueblos, en el caso ruso respecto de los procedentes de las estepas asiáticas y en el alemán oponiéndose al mundo romano que llega desde el otro lado del Rin ${ }^{58}$. Por su parte, el fascismo italiano prefiere buscar sus raíces geográficas - además de en la romanità - en la naturaleza de las áreas montañosas, que aportan valores y esencias al pueblo italiano ${ }^{59}$.

Frente a estos casos, en España la valoración de los paisajes y su relación con la identidad nacional maneja referencias propias desde el siglo XIX, con un protagonismo destacado de los escritores y pintores de la generación del 98 y de la Institución Libre de Enseñanza, que cristalizan en la personalización de la identidad colectiva nacional con los rasgos sencillos y rotundos de los paisajes castellanos ${ }^{60}$. El franquismo recoge en buena medida esas nociones paisajísticas y las exacerba a nivel retórico con una finalidad política claramente diferente a la de los movimientos culturales citados. Esa lectura del paisaje - en palabras de Zira Box - tiende, por un lado, a dotarle de fervor nacional, pues se proyecta sobre el territorio la historia, los mitos o las gestas nacionales; por otro lado, se proclama una relación determinista de la nación con el paisaje, pues éste le confiere al pueblo carácter. Y, por último, el paisaje tiene la capacidad de emocionar a quien lo contempla con una determinada sensibilidad patriótica y franquista ${ }^{61}$.

57 Wolschke-Bulmahn, 1997; McNeill, 2000; Agnoletti, 2003; Bruggermeier, Cioc \& Zeller, 2005; Imort, 2005a y 2005b; Brain, 2010; Armiero, 2011; Chapoutot, 2012; Armiero \& Graf von Hardenberg, 2013; Box Varela, 2016.

58 A partir de las ideas de Schama, 1995, sobre la memoria y el paisaje ejemplificadas para el caso alemán, se pueden consultarse también: Imort, 2005, p. 56-59 o Brain, 2010, p. 673 para la URSS. 59 Armiero, 2011 y Armiero \& Graf von Hardenberg, 2013. Con mayor amplitud, John McNeill, 2000, 325-356 resume algunas posiciones de los nacionalismos y sus ideas de la naturaleza.

60 Ortega Cantero, 2007. Una síntesis de lo escrito a este propósito y de las diferencias entre los clichés de los paisajes nacionales españoles y los de los nacionalismos periféricos en García Álvarez, 2009, p. 186-188. Véanse también García Álvarez, 2003 y Nogué i Font, 2005.

61 Box Varela, 2016. 


\section{Cuelgamuros. Elección del lugar y valoración de su paisaje}

Las coordenadas anteriores sobre la relación de los regímenes autoritarios en diversos países con la naturaleza y el paisaje se manifiestan con nitidez y de forma ejemplar en el Valle los Caídos, desde aquellos aspectos que tienen que ver con la elección del lugar en el que se levantó la obra, pasando por la valoración de sus paisajes con la retórica franquista y su adaptación al relato del turismo que lo visita, hasta la valoración actual y protección de ese territorio.

El relato oficial sobre la elección del emplazamiento del Valle de los Caídos sitúa a Franco en la primavera de 1940 frente al Risco de la Nava, acompañado por el General Moscardó, con quien buscaba desde hacía tiempo un lugar para el monumento. Ante el panorama de Cuelgamuros sentencia: "No se trataba de descubrir nada. Me desazonaba de impaciencia por identificar y localizar una imagen que llevaba dentro de mí hacía tiempo. Sabía, ciertamente, que existía, pero no sabía dónde." Y después de admirar esa belleza que subyugaba advierte "subiremos otro día; y me atrevo a esperar que subirán muchos españoles"62.

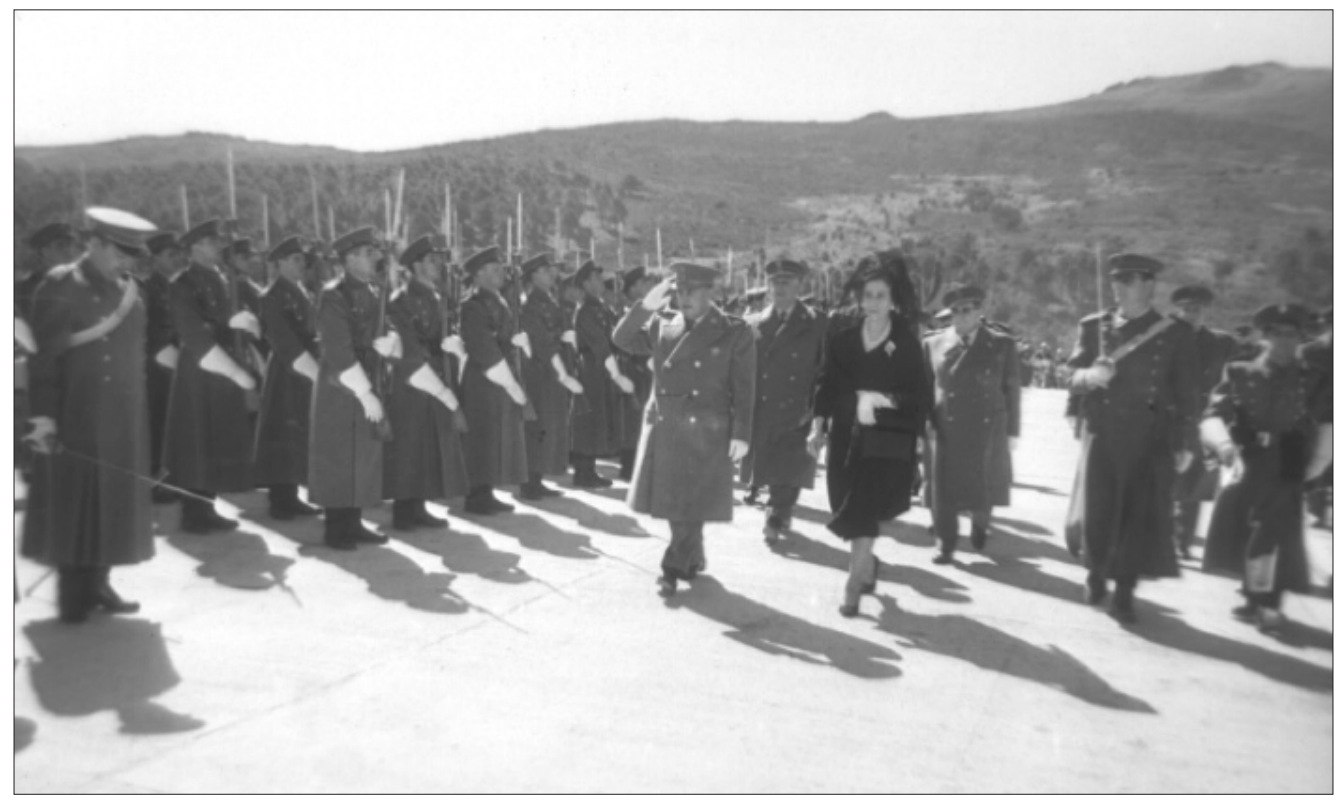

Figura 4. Franco pasa revista en la inauguración del Valle de los Caídos, 1959. Fuente: ARCM. Fondo Santos Yubero, sig. 016797_013.

La intencionalidad de emparejar el Valle de los Caídos con El Escorial, tanto en lo que respecta a su emplazamiento y elementos constructivos, como a las cuestiones simbólicas es evidente ${ }^{63}$. Las simetrías intencionadas abarcan desde la posición, estilos, materiales, semejanza de intenciones conmemorativas, sepulcrales y de presencia religiosa, llegando al discurso mismo de su fundación: la búsqueda del

62 Este relato lo escribió el abad del Valle de los Caídos, Justo Pérez de Úrbel en 1959, y ha sido divulgado durante décadas en las guías oficiales editadas por Patrimonio Nacional y un sinnúmero de guías y publicaciones turísticas, lo que causa sonrojo.

63 Madrazo García de Lomana, Lacasta Reoyo \& Saez Pombo, 2017, p. 1260-1261. 
lugar y el regocijo del monarca y del caudillo ${ }^{64}$. Todo es notorio y hasta previsible en el paralelismo, por lo que ha sido abundantemente estudiado, particularmente en lo que hace a la inspiración que el Escorial supuso para la arquitectura del primer franquismo y, asimismo, por el uso y abuso del monumento y de su interpretación histórica ${ }^{65}$. Y en un sentido más divulgativo, el intencionado mestizaje de los discursos y su evidente cercanía condujo y sigue conduciendo a que se asocien El Escorial y el Valle de los Caídos como recurso turístico, cuando no enlazados a destinos como Toledo, Ávila o Segovia con itinerarios publicitados como "ruta imperial", etc., tal y como demuestran los mapas de las guías oficiales de Patrimonio Nacional.

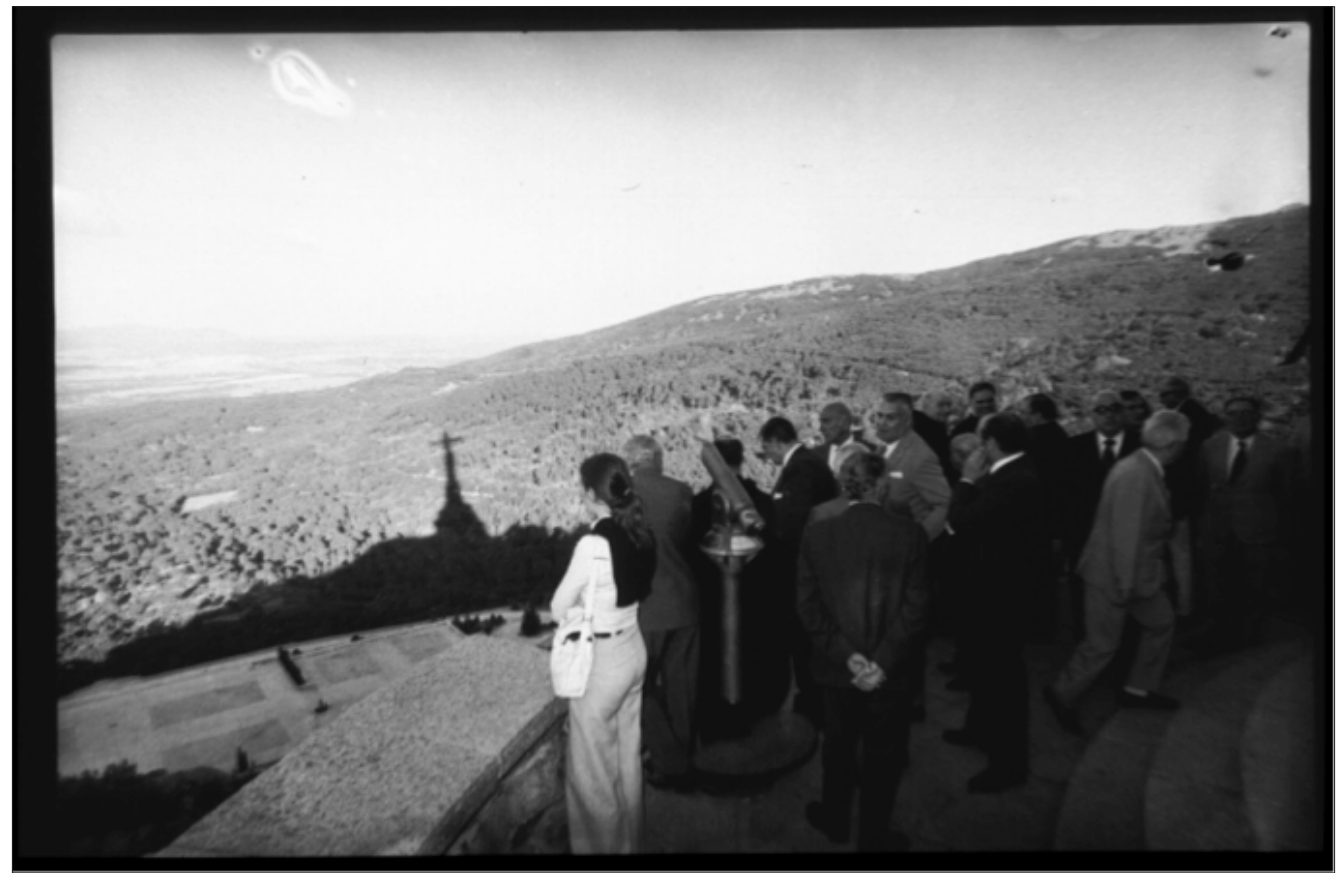

Figura 5. Fotografía del Valle de los Caídos en 1975.Bajo la silueta de la cruz las repoblaciones forestales en el monte de Cuelgamuros forman ya un monte denso. Fuente: ARCM. Fondo Santos Yubero, sig. 34160_003

Respecto de las valoraciones del paisaje, que arrancan con la casi mítica elección del emplazamiento, resultan recurrentes los tópicos que remiten vagamente al pasado glorioso que representa Felipe II, con alusiones a los horizontes velazqueños, a la soledad y al misticismo del lugar, aumentados por la austeridad de la roca viva y de la vegetación escasa ${ }^{66}$. Valgan como muestra de lo dicho las valoraciones paisajísticas que acompañan a la guía oficial del Valle de los Caídos: "es la montaña austera y fuerte, aunque no le faltan abundancia de regatos, frondosidad jugosa y

64 Así, las crónicas más conocidas sobre la fundación de El Escorial, que imitarán luego las del Valle de los Caídos, hablan de que Felipe II "comenzó a observar si en sus cercanías -de la Corte- se hallaría algún sitio a propósito para levantar el grandioso edificio que había dibujado en su alma" (Quevedo, 1849, p.4) o de que, tras valorar otras opciones, en El Escorial había "grande copia de hermosa piedra cárdena, que no parece sino que toda la gran fábrica es de una pieza y cavada en una peña" (Sigüenza, 1605, p. 14-15).

65 Entre otros muchos Llorente Hernández, 2002; Hermoso Cuesta, 2017.

66 Pérez de Úrbel, 1959; Méndez, 1982. 
parajes llenos de gracia y amenidad. En la cabecera, solitario y firme, se alza el risco de la Nava, de recortadas piedras y ariscas laderas." ${ }^{67}$.

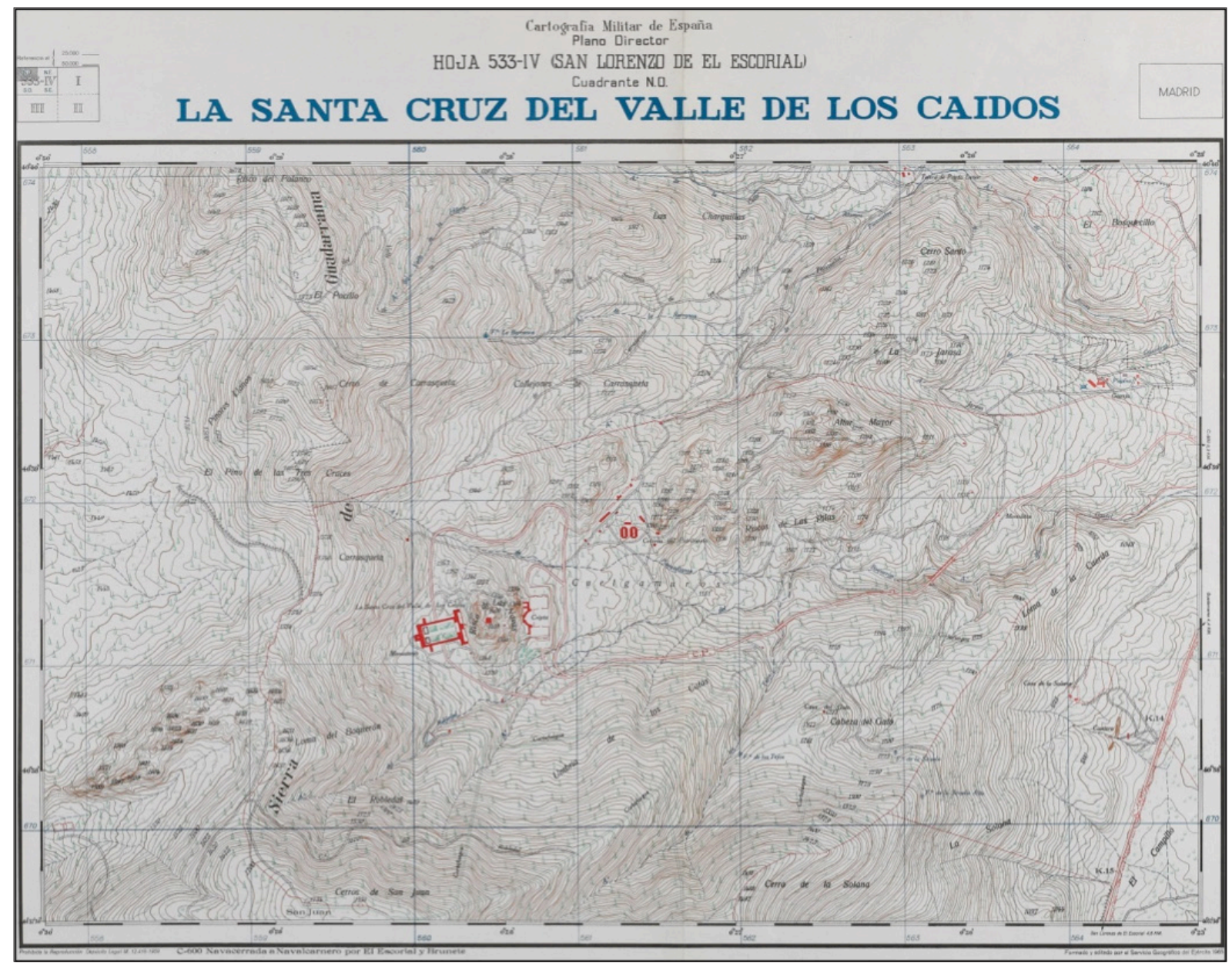

Figura 6. Mapa Topográfico Nacional del cuadrante NO del cuadrante IV de la hoja 533 del Servicio Geográfico del Ejército (SGE), escala 1:10.000, editada en 1965. Es una de las pocas hojas editadas a esta escala por el SGE.

Fuente: BNE, Geografía y Mapas, sig. MR/28/1/13 H. 533-IV

Para finalizar, en línea con las anteriores valoraciones paisajísticas, aunque más elaborada, valgan las palabras de Gaspar Gómez de la Serna: “El propósito de este monumento nacional a todos los caídos en la fratricida guerra de 1936-1939, de personalísima iniciativa de Franco, es paralelo al que movió a construir El Escorial en el sentido de que se trata a la vez de una acción de gracias y de una conmemoración piadosa; paralelismo que acentúa no solo la proximidad del lugar y la identidad del paisaje, sino estar incorporado a éste más aún que el Escorial, formando parte de él"68.

67 Patrimonio Nacional, 1959. Poco difieren las palabras de Pérez de Úrbel, que al hablar de la Sierra de Guadarrama y sus valles dice que "tal vez el más esplendido de todos es el de Cuelgamuros, con manchas extensas de rica vegetación serrana; el pino, la jara, el roble y el chopo, en las partes más honda, y austeros salientes rocosos, cuyos picachos bravíos revisten bellas y caprichosas formas", Pérez de Úrbiel, 1959, p. 8.

68 Gómez de la Serna, 1963, p. 260; citado por Hermoso Cuesta, 2017, p. 301. 
La colección de calificativos repetitivos y empalagosos que ofrecen las guías y textos que exaltan el Valle de los Caídos permitiría llenar muchas páginas, pero se pueden sintetizar en la común aspiración de todos ellos de mostrar una emoción exacerbada ante este paisaje, dotándolo de unos valores nacionales y determinantes para sus habitantes ${ }^{69}$. Valga como ejemplo la siguiente valoración del paisaje: “Todo en este escenario es de una armonía perfecta; los montes que le ciñen y fecundan con las nieves invernales, los recodos y laderas que se agazapan medrosamente entre las gargantas, la alta pirámide central, que parecía como el pedestal en espera de la obra gigante ideada por el genio"70.

La fijación de convertir el Valle de los Caídos en un espejo del monasterio de El Escorial y en un hito de la Sierra de Guadarrama se alcanzó con la obra mastodóntica que lo hace visible desde gran distancia, pero su significado está lejos de ser una referencia común, se ha convertido más bien en algo incómodo y problemático de cara al futuro. Patrimonio Nacional, en calidad de administrador provisional, maneja un tono aséptico en la presentación del monumento - al que denomina Abadía de la Santa Cruz del Valle de los Caídos-, si bien se extiende algo más a la hora de valorar el paisaje y el medio ambiente del Valle de Cuelgamuros - como lo denomina en su web ${ }^{71}-$, abandonando el tono encendido de las primeras guías sobre el Valle de los Caídos en favor de un discurso más técnico.

Desde el punto de vista de la protección y gestión de este territorio, la finca Cuelgamuros es desde 1940 propiedad de Patrimonio Nacional, quien administra interinamente la fundación de la Santa Cruz del Valle de los Caídos. Aparte de esto, desde el punto de vista de la protección natural, la finca se encuentra dentro del LIC-ZEC de la Cuenca del Río Guadarrama y, en lo que hace a la masa forestal, Cuelgamuros y los montes de La Solana y La Pizarra -vecinos de este al sur-, en tanto que antiguos montes consorciados por el Patrimonio Forestal del Estado, se encuentran gestionados a día de hoy por la Comunidad de Madrid.

No se puede dejar de hacer referencia a la reciente declaración como Bien de Interés Cultural del territorio histórico de la cerca de Felipe II (Decreto 52/2006 20 de julio; BOCM, 21 junio 2006), valorando a tal fin la idea de que el conjunto monumental del Monasterio de San Lorenzo "no se concibe como un elemento aislado en el paisaje, sino como la pieza central de un complejo sistema", que incluye caminos, paseos, puentes, jardines y dehesas.... La coherencia territorial a la que alude la declaración para englobar casi $100 \mathrm{~km}^{2}$ no se hace extensible a Cuelgamuros, aunque originalmente sí que se encontraba dentro del territorio de la Cerca, optando por no aceptar las alegaciones referidas a su incorporación "por tratarse de un bien de

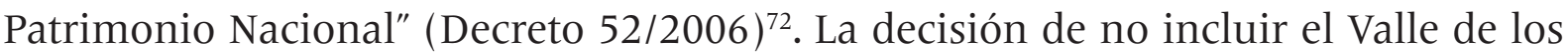

69 Box Varela, 2016.

70 Pérez de Úrbel, 1959, p. 9.

71 Web de Patrimonio Nacional, secc. Medio Natural <http://www.patrimonionacional.es/medionatural> consultada el 1 de marzo de 2018

72 Madrazo García de Lomana, Lacasta Reoyo \& Saez Pombo, 2017, p. 1259-1261. 
Caídos dentro del BIC seguramente sea oportuna, pero su justificación es confusa, como casi todas las decisiones políticas sobre el monumento.

Desde esta óptica patrimonial, interesa para el entendimiento de memoriales como el Valle de los Caídos, la diferenciación entre "paisaje político" y "paisaje vernáculo", el primero "caracterizado por el acto fundador de despliegue del poder y la creación de un territorio que encarna a ese poder" y el segundo como "el paisaje de vida de los vecinos y de las comunidades, cuya construcción se va haciendo de modo secuencial"73. El significado político de Cuelgamuros y la memoria que sigue representando, vinculada al mantenimiento de su sentido original ${ }^{74}$, lo convierten sin duda en un paisaje político. Al compararlo de nuevo con el paisaje del Monasterio de El Escorial y su entorno, igualmente ordenado por un despliegue de poder en el siglo XVI, contrasta que en este último el reconocimiento social unánime de sus valores lo han convirtido en un paisaje vernáculo, mientras que en el estado actual de las cosas en ningún caso se espera que el Valle de los Caídos y Cuelgamuros alcancen esa identificación.

\section{El forestalismo español y las repoblaciones ornamentales}

Centrando ahora la atención en el proceso concreto de repoblación en torno al monumento de los caídos, es oportuno reflexionar acerca de la idea de paisaje de los ingenieros de montes de la época, o más en concreto en cómo éstos incorporan en el discurso que justifica la reforestación la intención de "crear paisajes", entendidos como escenarios técnica y estéticamente más adecuados que "los desarbolados" o "rasos". Es decir, además de las dos finalidades - la protección y la producción- más conocidas, estudiadas y valoradas de las repoblaciones, la intención estética y ornamental tuvo cierta relevancia, más que por su amplitud superficial, por la visibilidad y el significado de algunas de éstas intervenciones alrededor de carreteras, en espacios verdes urbanos o en lugares emblemáticos por su significado político, entre los cuales destaca el Valle de los Caídos ${ }^{75}$.

Por ello desentrañar el bagaje y claves del pensamiento paisajístico de los Ingenieros de Montes españoles y su repercusión sobre la ejecución de los trabajos forestales alrededor de ámbitos muy transitados, monumentos emblemáticos o zonas bien queridas por el régimen en las proximidades de Madrid, es imprescindible. Al fin y al cabo fueron ellos los que "vistieron con árboles" el escenario del monumento de Cuelgamuros.

\footnotetext{
73 Gómez Mendoza, 2013, p. 6-8.

74 Esa 'resignificación' es la idea fundamental que se emplea en el Informe de la comisión de expertos sobre el futuro del Valle de los Caídos, Ministerio de la Presidencia, 2011.

75 No es posible citar aquí todos los trabajos que han analizado las implicaciones territoriales de las repoblaciones franquistas en diferentes ámbitos geográficos. Cabe mencionar, sin ánimo de exhaustividad, el trabajo pionero a escala nacional de Gómez Mendoza y Mata Olmo, 1992 o los muchos que indagan, a escala regional y comarcal, la diversidad e implicaciones del proceso reforestador: Araque Jiménez \& Sánchez Martínez, José Domingo, 2009; Muñoz Jiménez, 2016; Uriarte Ayo 2010; Rico Boquete, 2008a, 2008b y 2016.
} 
En primer lugar, cabe advertir que esa preocupación de los forestales por el paisaje no es nueva, sino que arranca desde el momento mismo de la introducción del forestalismo moderno en España a mediados del siglo XIX y se amplifica a partir del cambio de siglo, cuando las preocupaciones de ingenieros y otros propagandistas forestales por el estado de los montes españoles se convierten en un lamento que atañe al paisaje en general ${ }^{76}$. Buen ejemplo de ello es la revista España Forestal, editada entre 1915 y 1929, en la que las referencias al paisaje son especialmente insistentes. En esa publicación, que patrocinó la Real Sociedad de Amigos del Árbol, se mezclan los elogios literarios a los bosques, la propaganda de las fiestas del árbol, la denuncia de talas, roturaciones u otras "perversiones del comunalismo" y el lamento por incendios, inundaciones y otras catástrofes, que en conjunto se interpretan como el síntoma del mal estado de los paisajes y que quieren servir para crear un estado de opinión favorable a la restauración forestal.

En las décadas de 1940 en adelante, las concepciones del paisaje estuvieron presentes en las actuaciones de la administración forestal, manifestándose particularmente en la obra de repoblación ejecutada en toda España por el PFE y, posteriormente, por el ICONA. En este sentido, hay que tener muy presente que, como dice Josefina Gómez Mendoza, "la actitud de los ingenieros ante el monte y el bosque no es sólo contemplativa y científica, es también transformadora. (...) Son creadores de paisajes"77. De este modo, para los ingenieros de montes el paisaje se convirtió per se en un argumento para reforestar. Es decir, entre las razones que justificaban las repoblaciones forestales se encontraba la de crear paisajes bellos. Por ejemplo, el Boletín Informativo del Patrimonio Forestal del Estado78, informaba de que las Repoblaciones forestales en el Plan de Desarrollo en 1965 se diferenciaban entre " $1{ }^{\circ}$ Trabajos hidrológico forestales, de función eminentemente protectora...; $2^{\circ}$ Repoblaciones de producción...; $3^{\circ}$ Repoblaciones de carácter ornamental para mejora de paisajes y creación de zonas verdes para esparcimiento y recreo"79.

Ahora bien, sabiendo que los ingenieros del PFE eran conscientes de su papel transformador del paisaje, es imprescindible preguntarse qué significa el paisaje para ellos y a qué paisajes aspiran. Tras revisar planes y publicaciones periódicas de la época, se comprueba con curiosidad que el paisaje se convirtió en un argumento recurrente para repoblar, pero la reflexión acerca de los paisajes fue escasa. Es decir, apenas existió debate o reflexión acerca del tipo de repoblación a realizar o de las composiciones logradas, sino que predomina la actitud iterativa de considerar que el arbolado mejoraba el paisaje en todo caso. "Desde el punto de vista del paisaje,

\footnotetext{
76 La raíz del discurso paisajístico de los ingenieros de montes españoles ha sido retratada en varios trabajos por Josefina Gómez Mendoza, 1992 y 2002.

77 Gómez Mendoza, 2002, p. 239.

78 Boletin Informativo del Patrimonio Forestal del Estado, 1965, n³, p. 54-60.

79 Las 94.000 ha repobladas en 1964, primer año del Plan, se habrían distribuido respectivamente, según esta clasificación, en un 58\%, un 30\% y un 12\% para las forestaciones ornamentales. Gómez Mendoza y Mata Olmo, 1992, p. 36.
} 
esto equivalía a establecer paisajes de primera y de segunda, y los no arbolados se encuentran por definición entre los segundos"80.

La presencia del término paisaje asociado tanto a los espacios forestales de reconocido valor - Parques Nacionales y Sitios Naturales de Interés Nacional- como a las intervenciones silvícolas y a las repoblaciones con finalidad estética y ornamental, es también importante en los artículos publicados en la Revista Montes entre 1940 y 1960. Respecto a estas segundas, Joaquín Ximénez de Embún plantea en un artículo que "los bosques son bellos y su existencia fundamental para mantener la belleza del paisaje", por lo que la intervención técnica para su conservación y fomento se fundamenta en razones "estéticas", pero también éticas. Se trata de "mantener esa belleza para que por ella y a su través se cumplan los fines buenos que el bosque tiene" entre los que se encuentra la capacidad de tranquilizar y hacer reflexionar al hombre que lo contempla "mejorando el envenenado carácter", pues proporciona bienestar espiritual. El Ingeniero de Montes debe atender a las funciones estéticas buscando las intervenciones que conduzcan a "paisajes tipos" que sean bellos y cumplan también con las funciones de orden económico ${ }^{81}$.

Lo interesante es que Ximénez de Embún, a partir de este planteamiento que relaciona lo bello con lo bueno, la estética con la ética y el bienestar espiritual con las necesidades materiales, concluye el tipo de intervención silvícola más adecuada para atender la "estética del bosque" sin descuidar el resto de sus funciones. De manera elocuente y como él mismo reconoce, simplificada, establece: "que el bosque bello no puede obtenerse más que con método de beneficio de monte alto; otro que, salvo contadísimas excepciones en bosque de coníferas de montaña los efectos estéticos no pueden conseguirse más que con masas semi-irregulares o regularmente irregulares, lo que indefectiblemente lleva a los tratamientos de cortas por bosquetes o entresacas regularizadas (...). En definitiva el método de ordenación que mejor se compadece con la finalidad estética del paisaje forestal de montaña es la entresaca regularizada ${ }^{82}$. Propone también el autor cómo se deben elegir las especies más acordes con el paisaje-tipo de la zona, "buscando combinaciones de verdes, puntos de vista y acogedores rincones en la apertura de caminos, calles, cortafuegos"..., para rematar que un verdadero forestal debe de tener "el alma de poeta y el corazón de artista" 83 .

En 1960 otro ingeniero, Lorente Sorolla, en un artículo titulado “Repoblaciones ornamentales en la estética del paisaje" retoma las ideas de Ximénez de Embún y tras definir el paisaje como "un estímulo a la emoción estética" considera que la vegetación, los montes, contribuyen de forma decisiva a la belleza de los paisajes". A partir de ahí centra su atención en cómo debe ser la vegetación para que tenga mayor valor paisajístico y propone que se repueble con criterios ornamentales si no existe vegetación o cuando sí exista se busque el contraste y la diversidad en el espa-

80 Gómez Mendoza, 2002, p. 241.

81 Ximénez de Embún, 1948, p. 306.

82 Ibíd.p. 307.

83 Ibíd. p. 308. 
cio y en el tiempo. Asimismo, alude al equilibrio entre estratos herbáceo, arbustivo y arbóreo, a diversidad de espacies buscando contrastes de portes y colores y variabilidad estacional en función de los ritmos de floración y de caída de las hojas. ${ }^{84}$

Menudean también en las publicaciones de esta etapa las alusiones a la oportunidad de participar en la conservación y creación de jardines y parques urbanos como "ornamento y lugar de expansión de los ciudadanos" y como "telón de fondo de la ciudad". Se destacan, además, en el caso de Madrid, las intervenciones en lugares emblemáticos de la ciudad, como las de la Casa de Campo o la Ciudad Universitaria $^{85}$, y ampliando el foco, también se considera imprescindible embellecer los montes de la Sierra del Guadarrama, cuyos "valores estéticos y posibilidades recreativas y de reposo" son de especial relevancia dada su proximidad y visibilidad desde la capital. En un contexto de éxodo rural y crecimiento urbano, los técnicos forestales inciden en los valores "estéticos" y "recreativos" de los espacios forestales, es decir en la función de embellecer los espacios urbanos y atender a las necesidades de los ciudadanos ${ }^{86}$.

Otra cuestión presente en el discurso de los forestales de la época son las repoblaciones de los bordes de las carreteras. Además de su carácter funcional (dar sombra y mayor seguridad a los automóviles), se consideran también de finalidad estética en un doble sentido: integrar las vías en el paisaje que atraviesan y hacer más amena la vista a los conductores ${ }^{87}$. También se percibe la intención de embellecer zonas muy transitadas con un sentido de propaganda de las intervenciones territoriales del régimen en general y del Patrimonio Forestal de Estado en particular. Las repoblaciones "paisajísticas" del puerto de Despeñaperros son el estandarte de este género de intervenciones, destacando que pueden tener impacto económico al fomentar el turismo, pero sobre todo valorando de forma grandilocuente "que el Patrimonio Forestal del Estado haya tomado sobre sí la tarea de recrear una riqueza nacional que estaba perdida, o en camino de perderse, es bueno. Que haya tomado la de crear riqueza y hacer arte - un arte vivo- es excelente" ${ }^{\prime \prime 8}$. Y unos años después, se incide en este sentido propagandístico y político de las repoblaciones linderas a las a las carreteras: "el Patrimonio Forestal del Estado contribuye a la formación del paisaje dedicando especial atención a las zonas contiguas a las vías principales de comunicación, exhibiendo así, además, una muestra del esfuerzo realizado en los 25 años de paz" 89 .

Sobre la cuestión de las carreteras, el paisaje y la repoblación destacan, sin duda, las reflexiones, ya en 1966, de Filiberto López-Cadenas. Su discurso enlaza con las

84 Lorente Sorolla, 1960.

85 García-Escudero y Fernández Urrutia, 1941. El que fuera primer Director de la Escuela de Ingenieros de Montes tras la Guerra Civil manifestaba en 1941 el valor simbólico y escénico de la naturaleza y el paisaje en el proyecto de repoblación de la Ciudad Universitaria, encargado a la Escuela de Montes y redactado por Luis Ceballos y Federico Blein.

86 García-Escudero y Fernández Urrutia, 1956, p. 235-236

87 Arbolí Hidalgo. 1958.

88 Jiménez Zayos, 1964, p. 50-51.

89 Revuelta Salinas, 1967, p. 363. 
ideas anteriores pero es más completo: en el contexto del impulso turístico de la época, señala que los trazados de las vías secundarias deben diseñarse procurando que faciliten panorámica a los paisajes. Sistematiza las funciones de las reforestaciones en los límites de las vías entre los objetivos de carácter utilitario (contención de taludes, control de erosión, crear zonas de descanso, orientar tráfico e, incluso, obtener madera) y los estéticos: integrar la carretera en el paisaje que atraviesa y destacar u ocultar de determinados puntos de vista. Esta idea es interesante: "claros en las plantaciones para disfrutar de la contemplación de elementos importantes del paisaje, un pueblo pintoresco, un puente, un castillo; mayor densidad para enmascarar perspectivas poco estéticas ${ }^{90}$.

La aplicación de estos discursos paisajísticos alcanza desde luego a los documentos técnicos de los montes gestionados por el PFE, es decir, los planes, proyectos o perímetros de repoblación, los procesos de adquisición y consorcio de fincas o las propuestas anuales de repoblación de los montes $^{91}$. Los ejemplos serían amplísimos, tanto como la ingente documentación que genero el PFE/ICONA entre 1940 y 1986; mencionaremos solo uno pero un simple ejemplo tomado de un proyecto de repoblación obligatoria alrededor de la Carretera N-I a su paso por la provincia de Segovia que ilustra el doble sentido de la mayor parte de las repoblaciones paisajísticas: por una parte "suavizar el duro paisaje de la meseta", "completar el panorama paisajístico de la carretera" o "dulcificar el paisaje" y, por otra, hacer propaganda de la labor del PFE en un lugar muy visible y por tanto estratégico, como demuestra la figura $7^{92}$.

En definitiva, se ha dicho en numerosas ocasiones que el Patrimonio Forestal del Estado fue un organismo con una capacidad ejecutiva sobresaliente. Así lo demuestran datos excepcionales como las 2.976 .708 ha repobladas entre 1940 y $1987^{93}$ o las 3.903.209 ha que gestionaba en 1980, por la vía de la adquisición o el consorcio. También fue decidido el PFE en lo que toca a la creación de paisajes y en todos los proyectos consultados el paisaje se entiende y aplica de manera casi similar: como escenarios de los que se aprecia la visibilidad de lo repoblado, publicitando los trabajos de repoblación.

Y ello es muy evidente en los numerosos proyectos de repoblación que afectan a fincas cercanas a carreteras de acceso Madrid: "Dada su situación perfectamente visible para los numerosos viajeros de alta categoría que diariamente recorren aquellos lugares"; "los trabajos muestran especial interés por lindar con una carretera de primer orden"; "un parque con el que se embellezca uno de los accesos de la capital..."; "Se pretende crear grupos de arbolado discontinuos y cercanos a la

90 López-Cadenas de Llano, 1966, p. 327.

91 Madrazo García de Lomana, 2010, p. 371-380.

92 FDM, Perímetros, Cj. 4858, Proyecto de repoblación obligatoria de perímetros próximos a la Carretera Nacional I.

93 Anuario de Estadística Agraria, años 1981 y 1988, Madrid, Ministerio de Agricultura. 
carretera"94. Una intención de propaganda de la labor del PFE, y por ende del régimen franquista, que se manifiesta con rotundidad en el caso de Cuelgamuros, como detalla en el siguiente apartado

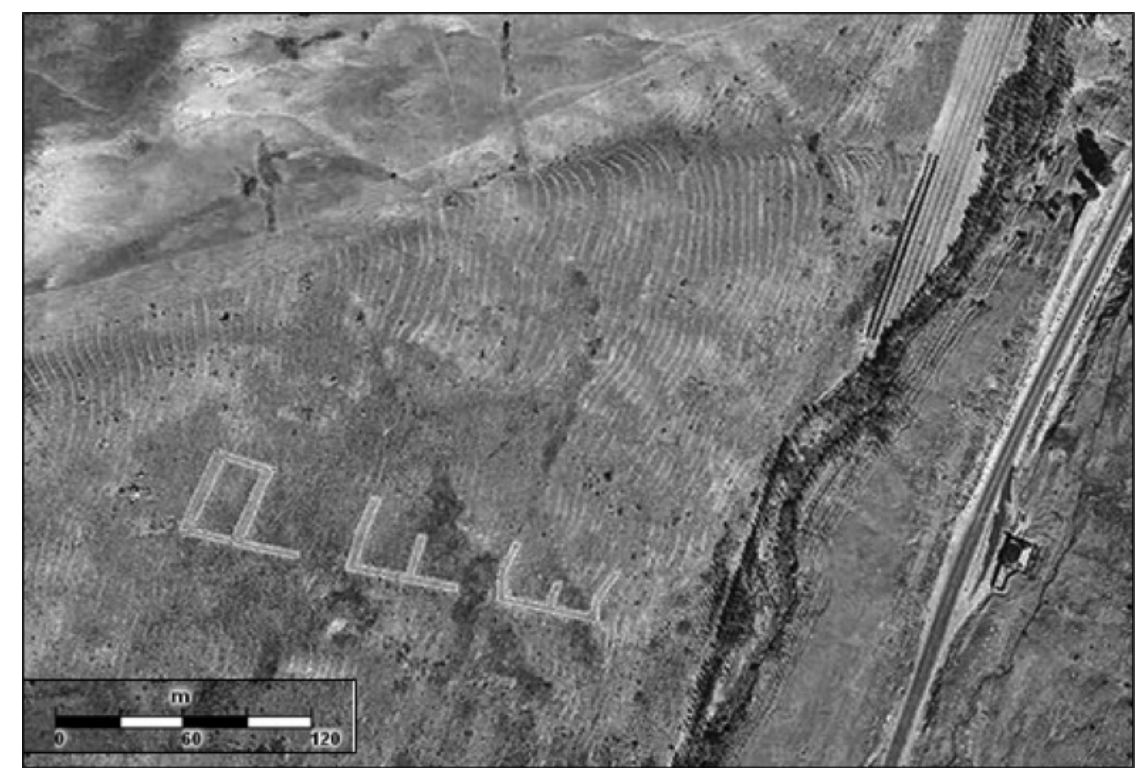

Figura 7. Fotografía aérea de la década de 1960 de un gran mosaico próximo a la N-I (Puerto de Somosierra). Monte de UP Juncadera, consorciado por el PFE, Santo Tomé del Puerto (Segovia).

Fuente: Visor .Planea-CAM. Fotografía aérea de 1961-67.

\section{La construcción del paisaje del Valle de los Caídos}

Al tiempo que se construía la basílica del Valle de los Caídos y se levantaba la cruz, en las décadas de 1940 y 1950, se reforestó el monte de Cuelgamuros, en el que se asienta el monumento, con la aspiración de crear un "marco digno de lo que allí se construía". Esas repoblaciones a nivel técnico no se diferencian sustancialmente de las que se hicieron en otras muchas zonas de España en esa época, pero el interés propagandístico del memorial exaltó el discurso político y técnico sobre la reforestación y los paisajes. En las siguientes páginas se reconstruirá el proceso de reforestación y el contexto y valoración paisajística de la construcción del Valle de los Caídos. Ello conlleva que se aborde, por un lado, la historia patrimonial del monte y, por otro, los trabajos concretos y las vicisitudes de su repoblación.

\section{Cuelgamuros antes del Valle de los Caídos}

La finca de Cuelgamuros formaba parte de los Bosques Reales del Monasterio de San Lorenzo del Escorial hasta 1837, cuando se exclaustra a los monjes y las 7.283 ha de su propiedad pasan al del Patrimonio de la Corona. Cabe recordar que la génesis de los Bosques Reales del Monasterio de San Lorenzo del Escorial se remonta al si-

94 FDM, Repoblaciones, Cj. 1695, Propuesta de repoblación en el Monte de El Pardo, 1950. Cj. 1719, Propuesta de repoblación Dehesa de Marimartín (Navalcarnero), 1954. Cj. 1712, Propuesta de repoblación Monte de Valdelatas (Fuencarral), 1943 y Perímetros, Cj. 4797, Proyecto de repoblación de Terrenos adyacentes a la Carretera Nacional Madrid a La Coruña, 1953. 
glo XVI, entre 1565 y 1594, cuando la Corona primero compra y adjudica al nuevo monasterio las dehesas de La Herrería y La Fresneda y luego despuebla y otorga los términos de los pueblos de Monesterio y El Campillo (en cuyo término se encuentra el sitio de Cuelgamuros) al monasterio Jerónimo ${ }^{95}$. La propiedad de estas dehesas recaía en el Monasterio, pero el monarca tenía amplias prerrogativas, fundamentalmente cinegéticas, que mantuvo a lo largo de los siglos, hasta el punto de que dichas dehesas pasaron a formar parte del Patrimonio de la Corona en 1837, escapando de esta manera de la desamortización de Mendizábal. Sin embargo, en 1869 (Ley 18 dic.) se suprime el Patrimonio de la Corona y algunas de las fincas de los Bosque Reales del Monasterio quedaron a merced de la Ley de Desamortización General de Madoz $^{96}$.

Así, entre el mes de junio y julio de 1870 se anunciaron para su subasta pública en grandes lotes los bosques reales de El Escorial y se fueron rematando en los tres años posteriores ${ }^{97}$. El Cuartel Cuelgamuros se encontraba dentro de esas dehesas reales, por lo que fue enajenado y subastado (figura 8). La extensión con que se anunció la finca es de 2.190,72 (frente a la medición actual en el catastro de 1.365,97).

Se tasó en 354.200 pts ( 158 pts/ha), de las que unas 100.000 pts correspondían al valor del arbolado, y fue comprada el 28 de septiembre de 1872 por 317.095 pts ( 144 pts/ha) por un tal Leonardo Esteban Rosado, seguramente un testaferro ${ }^{98}$. Tras la venta en desamortización, la primera inscripción de la finca en el registro de la Propiedad es de 1875 y aparece como "Pinar de Cuelga Moros", con una cabida bastante ajustada a la real: 1.377 ha ${ }^{99}$. Desde su venta en desamortización la finca cambia de manos rápidamente: un año después del remate, en 1873, el primer propietario la vende a Eduardo Guillermo de Torres, quien a través de varias operaciones parciales de compraventa, entre 1873 y 1882, vende el proindiviso por mitad a Ángel Cano Sánchez y Ramón Martínez Gran, y un año después - 1883-ambos propietarios venden a Felipe Padierna de Villapadierna la finca Cuelgamuros por 250.000 pts, libre ya de cargas una vez pagados al Estado los diez plazos de la compra ${ }^{100}$.

En las mismas manos, las de los herederos de Villapadierna, permanecerá el predio hasta que, a través del Decreto 1 de Abril de 1940, se dispuso la construcción del monumento a los Caídos (Basílica, Monasterio, Cuartel de Juventudes) "para perpetuar la memoria de los caídos de nuestra gloriosa cruzada" en la finca de Cuelgamuros. El mismo decreto, al declarar de urgente ejecución las obras, permitió la

95 Sánchez Meco, 1995; Luzón García, 2013, p. 137-143.

96 Valenzuela Rubio, 1974.

97 Las consecuencias territoriales son tan explícitas como que el 94,45\% del término municipal de San Lorenzo de El Escorial fue objeto de esta desamortización (Valenzuela Rubio, 1974, p. 385) o como que se desamortizaron cerca de 6.800 ha de los antiguos Bosques Reales, salvándose solamente La Herrería y otras fincas menores (El Cerrado, El Romeral y El Navazo de la Pulga) (Madrazo García de Lomana, Lacasta Reoyo \& Sáez Pombo, 2017, p. 1246).

98 Valenzuela Rubio, 1974, p. 396-397 y Archivo General de Protocolos de Madrid (AGPM), Tomo 35.027, f. 239-.

99 Méndez, 1982, p. 299.

100 AGPM, Tomo 40.141, f. 1819- y Tomo 35.027, f. 239-. 


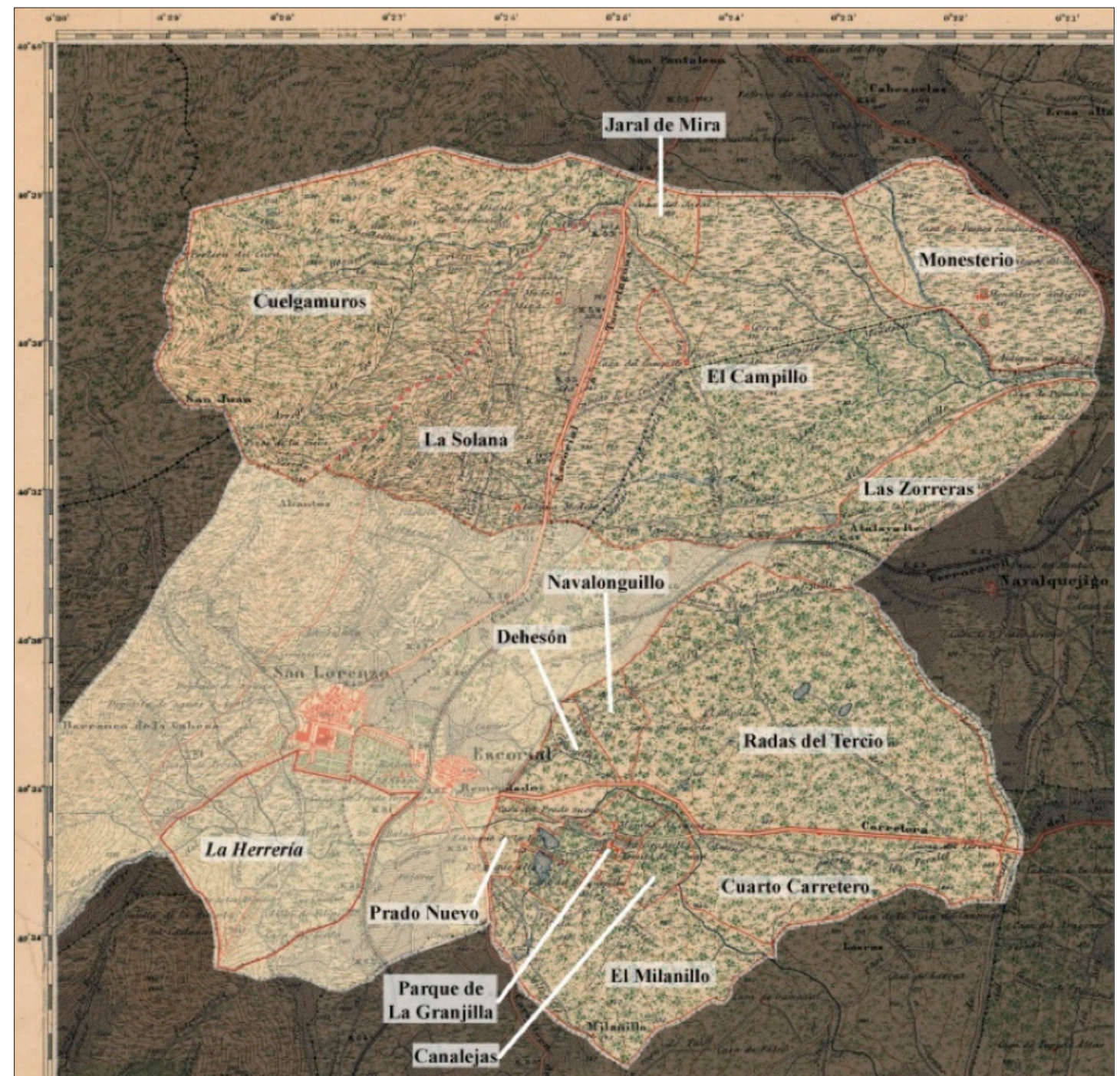

Figura 8. Fincas vendidas en desamortización en El Escorial sobre el Mapa Topográfico Nacional, 1877.

Fuente: Madrazo García de Lomana, Lacasta Reoyo \& Sáez Pombo, 2017, p. 1246.

expropiación forzosa de la finca de Cuelgamuros a favor del Patrimonio Nacional, pagándose a los propietarios - Gabriel Padierna de Villapadierna, Marqués de Muñiz, y herederos- 653.485 pts. por las 1.366 ha inscritas en el registro de la propiedad $^{101}$.

Las noticias sobre la cubierta forestal de Cuelgamuros a lo largo de la Edad Moderna y el siglo XIX son parcas, aunque se pueden desprender algunas ideas a partir de las solicitudes de aprovechamientos que llegan al prior del monasterio de San Lorenzo. Por ejemplo, desde el siglo XVI se conocen peticiones para la corta de pinos, aunque nunca en un número muy elevado, lo que concuerda con el hecho de que la mayor parte de los utilizados en la obra del monasterio procedieran de otros pinares, los de Peguerinos (Pinares Llanos) y El Espinar ${ }^{102}$. Otra constante entre los siglos XVII y XIX es que las peticiones para cortas se fundamentaban en la necesidad

101 Méndez, 1982, p. 299-302.

102 Luzón García, 2013. 
de cortar rodales que habían ardido o que se encontraban en mal estado -secos o tronchados- a causa de los vientos y nieves. En definitiva, estos aprovechamientos nos aproximan a la idea de que el paraje de Cuelgamuros, como dice un inventario previo a su desamortización, estaba cubierta la mitad por pinar y la otra mitad por monte y pasto ${ }^{103} \mathrm{o}$, más concretamente, que a finales del siglo XIX la finca, calificada de secano, "contenía peñas, aguas abundantes y buenas, así como pinos maderables, pimpollo de pinos, algunos fresnos, robles, matas de encina, retama, tomillo y piorno"104.

Después de 70 años, cuando Patrimonio Nacional compra Cuelgamuros para levantar el mausoleo, sólo 241 ha se hallaban pobladas con bosquetes irregulares de pino silvestre, negral y algunas encinas y enebros en la parte baja y media del mon$t^{105}$. Las interpretaciones de los técnicos encargados de llevar a cabo la repoblación aluden al argumento usual de que las "cortas forestales de excesivas extensiones, unido a los estragos del fuego, hicieron que este predio apareciese en el momento de su adquisición, en el año 1940, si no como un lugar desolado, sí como una superficie muy clara en algunos puntos, rasa por completo en otros, y con contadas manchas de pinar"106.

\section{Proyecto de repoblación}

Para mejorar el aspecto del escenario que acogería el monumento a los caídos, un año después de la compra de Cuelgamuros se encargó al Patrimonio Forestal del Estado (PFE) la labor de repoblar el monte de cara a formar un "marco digno de la obra que allí se construye" 107 . Inmediatamente se puso en marcha la repoblación de las vertientes peladas de la finca (figura 9) sin reparar, desde luego, en los gastos que pudiera conllevar, que fueron notables para el momento de primera posguerra, en relación a la inversión del PFE en otras zonas.

Claro que, obviamente, el coste de la reforestación palidece en comparación con la obra que se estaba levantando. En todo caso, la repoblación de Cuelgamuros tuvo prioridad absoluta, en tanto que sus dos fases se ejecutaron de forma inmediata ${ }^{108}$. Pero lo que más sorprende, y resulta revelador de la impaciencia por reforestar el mausoleo, es que no se esperó a redactar un proyecto de repoblación, que era lo que requería una finca de esa envergadura, máxime cuando el PFE siempre realizaba este tipo de proyectos ${ }^{109}$.

103 Op cit. p. 215-219.

104 AGPM, Tomo 35.027, f. 239 y siguientes.

105 González Aldama, 1964, p. 30.

106 Méndez, 1982, p. 301-302.

107 Decreto 31 de diciembre de 1941

108 De hecho, en los años que se acometen las repoblaciones en Cuelgamuros, éstas alcanzan un monto importante del dinero invertido por el PFE en la Sierra: 1942 el 47,5\%, 1943 el 42,2\%, en 1950 el 88,6\% y en 1952 el 27,1\%. Fondo Documental del Monte (FDM), Secc. Repoblación.

109 Ese proyecto de repoblación no se encuentra en el Fondo Documental del Monte (FDM), ni se conoce en la sección de bosques y jardines de Patrimonio Nacional, propietario de la finca y cuyo personal trabaja en ella, ni tiene noticias de él en la Dirección General de Medio Ambiente de la Comunidad de Madrid, a quien compete la planificación y gestión forestal del monte. Al comenzar 


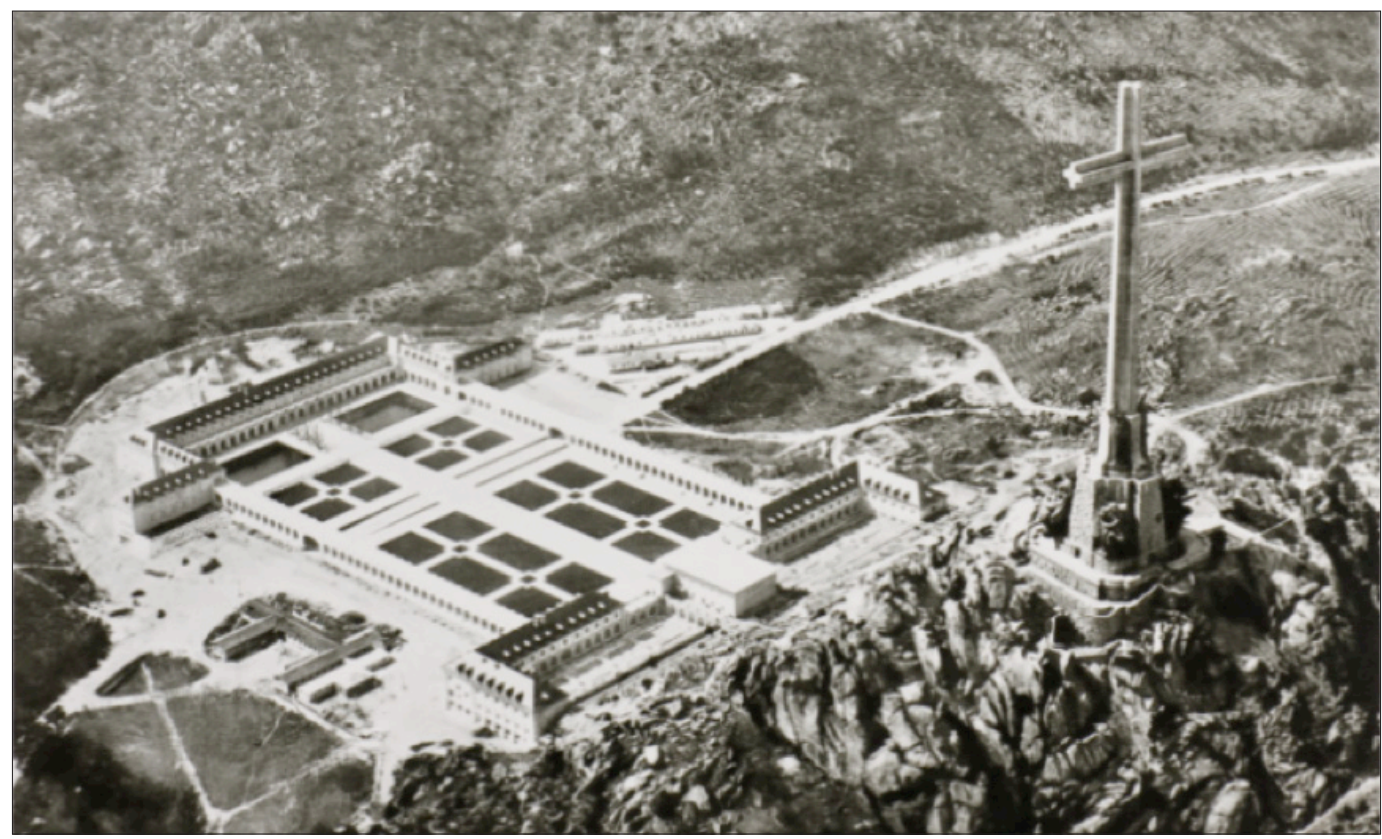

Figura 9. Imagen aérea de la Abadía de la Santa Cruz en 1959. Destacan las laderas aún rasas en las que se aprecian los surcos de las repoblaciones.

Fuente: Méndez 1982, p. 248.

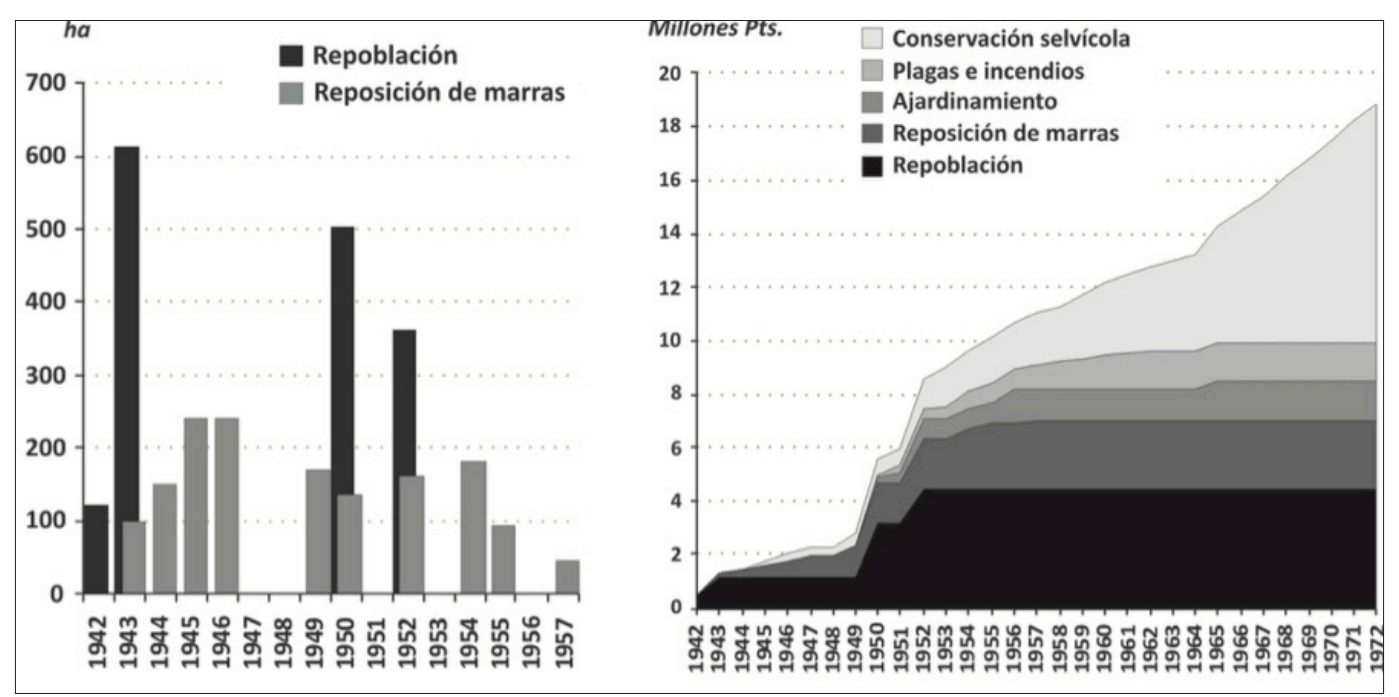

Figura 10. Ritmo de la repoblación (ha) y gastos ocasionados por conceptos (Pts. corrientes) en Cuelgamuros.

Fuente: FDM, Repoblaciones, provincia de Madrid, Caja 1740-1744.

La reforestación se inició en el año 1941 y progresó con gran rapidez, a pesar de que el monte no pertenecía al PFE, sino al Patrimonio Nacional, y por lo tanto se necesitaban autorizaciones del Consejo del Valle de los Caídos. Fruto de esa premura se repiten con asiduidad frases como que "Dado el carácter histórico y significado patriótico del monumento (...), la repoblación que se propone debe ser considerada

la reforestación se manifestó la intención de redactarlo: "ya tiene una idea el consejo de Patrimonio nombrado para la administración y dirección de las obras que allí se ejecutan, aunque no esté el citado proyecto totalmente concluido". FDM, caja 1740, Propuesta de repoblación Cuelgamuros, 1942. 
de interés nacional, por contribuir al embellecimiento de aquellos parajes, aparte de los beneficios que siempre lleva consigo la creación de masas arbóreas"110.

Los datos concretos que resumen el proceso de repoblación aparecen en la figura 10, demostrando que hubo dos periodos, antes y después del incendio forestal que afecto a la finca el 21 de Julio de 1950 y que destruyó buena parte de la obra ejecutada hasta aquel momento ${ }^{111}$. Dicho incendio se declaró en las laderas del Boquerón y el Robledal, en las vertientes O-SO de la finca, y destruyó buena parte de la obra realizada hasta entonces (figura 11 ).

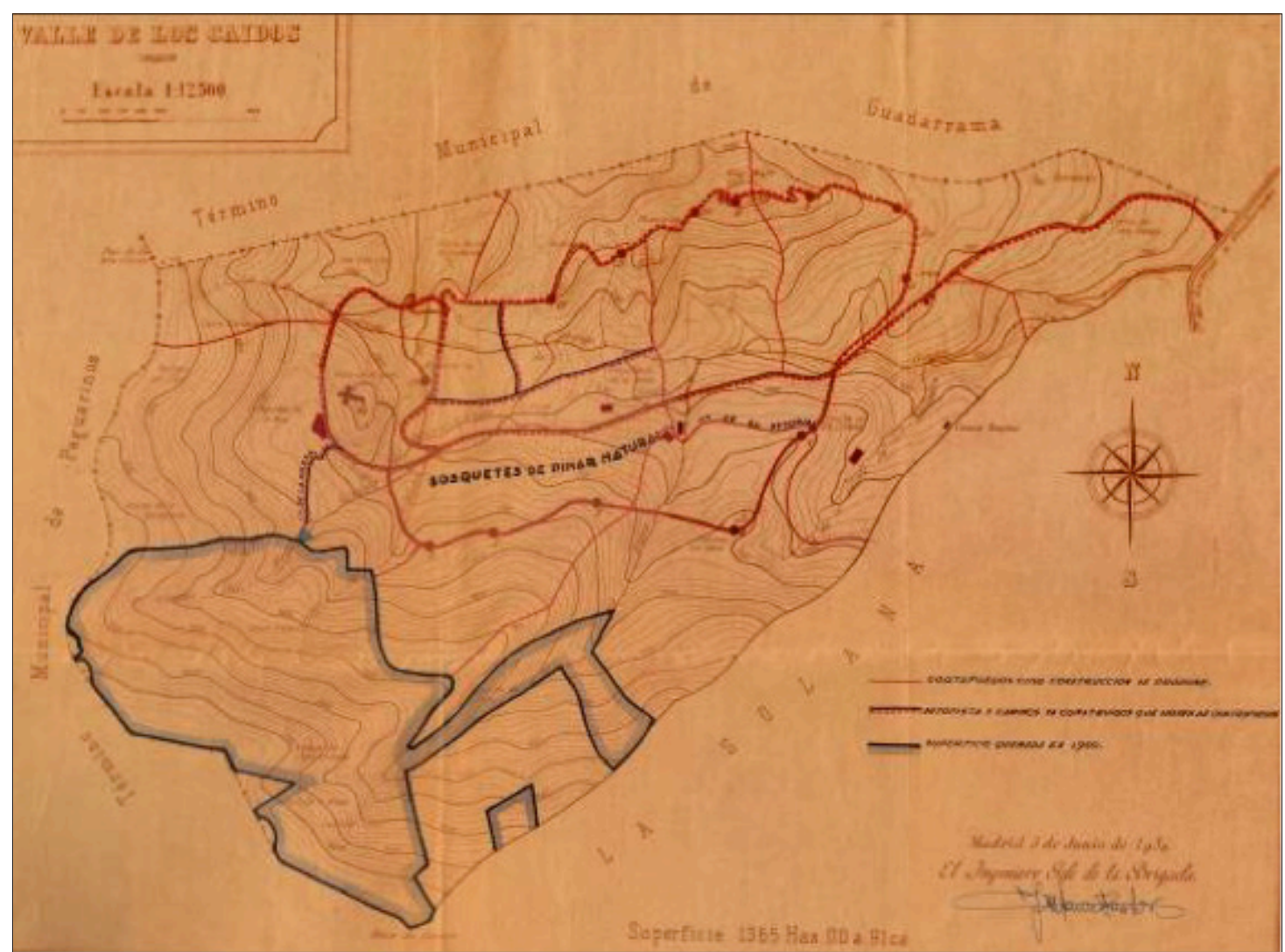

Figura 11. Mapa del PFE con la superficie afectada por el incendio de 1950.

Fuente: FDM, Repoblaciones, Mapa del incendio de Cuelgamuros, Caja 1740.

Oficialmente se habló de 277 ha consumidas, correspondiente a repoblados jóvenes y en la extinción participaron 640 obreros y, por si fueran pocos, el PFE nos recordaba que "en los trabajos de extinción de aquel incendio estuvo presente Su Excelencia el Jefe del Estado" ${ }^{\prime 12}$. La prensa de época apenas reflejó el incendio, a pe-

110 FDM, Caja 1740. Propuesta de repoblación Cuelgamuros, 1942; parafrasea el RD

111 Los datos definitivos del dinero empleado en la repoblación y otras labores silvícolas en Cuelgamuros no han sido fáciles de recabar, ya que como todo lo que rodea a la finca resulta opaco. En este trabajo se han manejado los datos resumidos que, por un lado, aporta Diego Méndez, 1982, p. 272, que como arquitecto de la obra debió conocerlos, pues en el Consejo del Valle de los Caídos participaba el Director General del PFE (Decreto 31 Julio de 1941). Por otro lado, se han usado los expedientes anuales (informes y presupuestos para la repoblación y otros trabajos silvícolas) que elaboraba el PFE y que se encuentran en el Fondo Documental del Monte (FDM). 112 González Aldama, 1964, p. 32. 
sar de la presencia de Franco en el mismo; así por ejemplo el ABC no aporta noticias hasta tres días después de que se declarase el incendio, lo que sorprende por su cercanía a Madrid. En dos escuetos párrafos se decía que "En San Lorenzo de El Escorial, el fuerte viento reprodujo el incendio, del que ya ayer dimos cuenta, en los pinares del monte de Cuelgamuros, lugar del monumento nacional a los Caídos (...). Hasta el momento no han conseguido sofocar las llamas"113.

Tras el incendio de 1950, que oficialmente quemó 277 ha, se informa de que en el monte perviven 251 ha, cuando deberían ser 442 ha si nos atenemos a las 719 ha repobladas en 1942-1943, pero lo cierto es que el incendio, unido a la gran cantidad de marras, hacen que se resuelva reforestar el monte por completo de nuevo. Por ello, en dos campañas consecutivas se trabajó sobre más de 800 hectáreas para culminar la reforestación, a lo que se añadió nuevas reposiciones de marras a lo largo de la década de 1950. La alta mortalidad del repoblado joven, debido fundamentalmente a las sequías estivales, se trató de resolver sobre todo llevando a cabo riegos y, por otra parte, se evitó también la plantación de pinos en trampales, praderas y arroyos, en los que se usaron frondosas a la espera de un éxito mayor y una "mejora del paisaje"114.

A la postre, cuando en 1959 se inaugura el Valle de los Caídos, de las 1.365,97 ha de la finca de Cuelgamuros, 1.123,73 ha estaban pobladas de árboles, el resto correspondía a los retazos de la vegetación previa y a zonas inforestales (afloramientos rocosos y zonas construidas). El esfuerzo por dotar al monumento de un "digno acompañamiento" forestal, supuso repoblar un total acumulado de 1.600 ha y reponer marras en un número prácticamente similar de hectáreas, 1.520. O dicho a la manera triunfalista del PFE en 1964: “... el Patrimonio Forestal del Estado ha plantado más de dos millones de árboles, que al sucederse en el tiempo harán patente, ante nuestros sucesores, la presencia de la España forestal en los actos más trascendentes de nuestra Patria"115.

En la repoblación de Cuelgamuros se utilizaron diversas especies. Como se ha dicho, sobre todo pino silvestre en las cotas superiores, pino negral en la más bajas y pino laricio intercalado, en consonancia con las manchas de vegetación que quedaban en el monte cuando lo adquiere el Patrimonio Nacional y de acuerdo, además, con los razonamientos ecológicos y forestales similares a los empleados en la mayor parte de las repoblaciones de la Sierra de Guadarrama ${ }^{116}$. Aparte de los pinos, para lugares significados de la obra como el Via Crucis, las vías de acceso o el entorno del monasterio se optó por ajardinar el monte con especies variadas: "alineaciones de Cupressus sempervirens y arizónica, bosquetes de Cedrus, Larix, Abies, Piceas, Chamecyparis, Sequoias, Libocedrus, Juniperus, Criptomerias, Ulmus, Populus, Salix, Quercus,

113 ABC, 25 Julio 1950 (p.18) y 26 Julio 1950 (p.11). Hemeroteca ABC.

114 "Tiene como fin estos riegos el evitar las costosas reposiciones de marras que de otra manera se producen inevitablemente y lograr la más pronta repoblación de un monte que se convertirá en el futuro en un Parque Nacional" (sic.), FDM, repoblaciones, Madrid, Caja 1741.

115 González Aldama, 1964, p. 33.

116 Madrazo, 2010, 373-380. 
Castanea, Fagus, Tilia, Betula y otras"117 (figura 12). El resultado, tal y como se presenta hoy día, es un monte en el que predomina la cubierta de pino silvestre y negral, pero también aparecen plantaciones singulares, con especies variadas, muchas de ellas exóticas, al igual que en otros espacios en los que la administración forestal justificó su obra de acuerdo con intereses estéticos o paisajísticos.

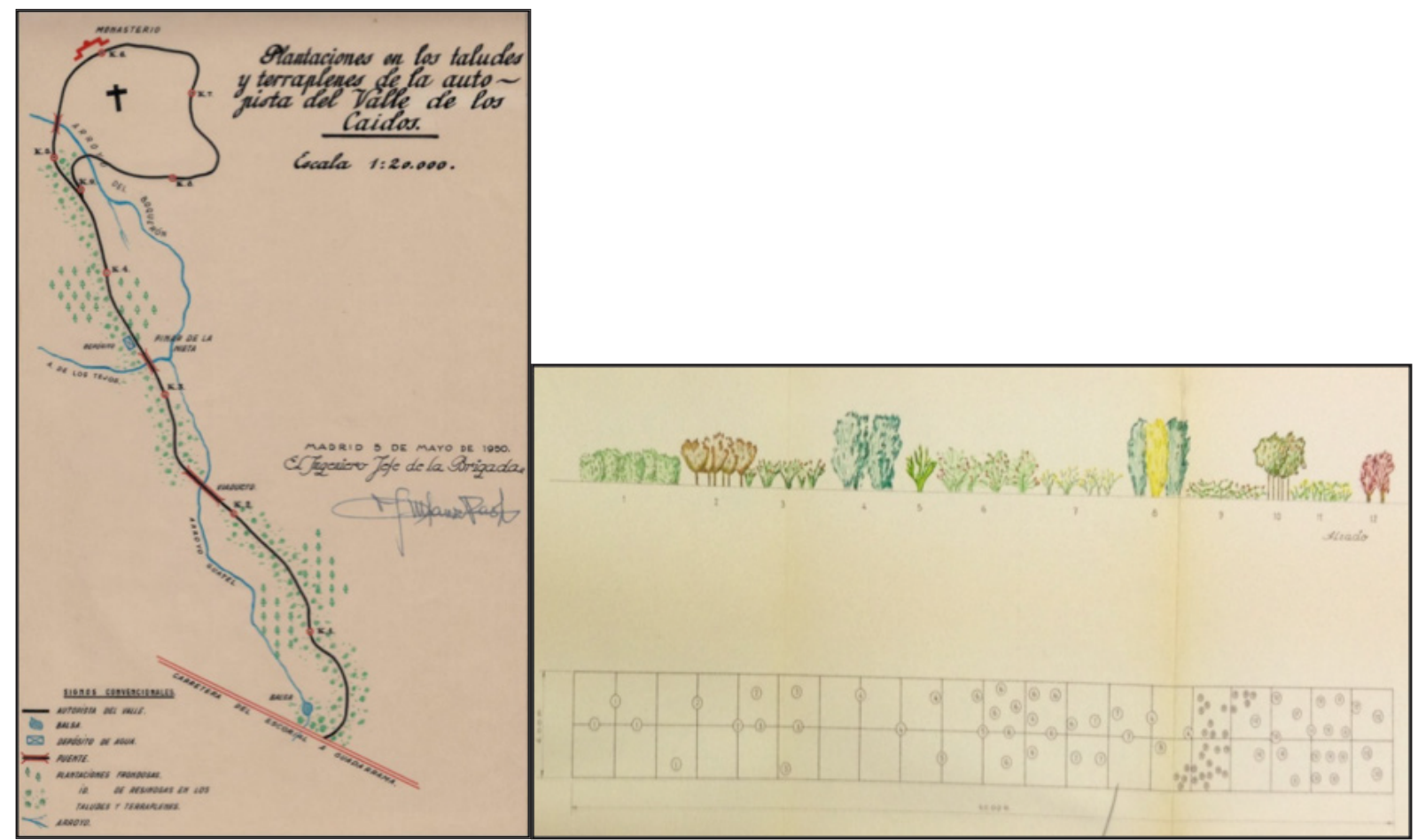

Figura 12. Mapas de las plantaciones ornamentales en torno de la carretera del Valle de los Caídos y dibujo del ajardinamiento en cerca de la abadía.

Fuente: FDM, Caja 1741.

A partir de la década de 1950 los gastos silvícolas y las obras forestales (podas, rozas, sacas, cortafuegos, etc.) ocuparán el grueso del presupuesto del PFE para el monte, lo que llevará a que, a la postre, se convierta en la partida más onerosa de los trabajos forestales realizados en Cuelgamuros. En menor medida las obras relacionadas con la vigilancia contra incendios y el control de plagas se encuentran muy presentes a lo largo de estas décadas, particularmente porque el repoblado joven se encontraba muy afectado por la plaga de procesionaria, afeando el paisaje de "un lugar de peregrinación nacional". El PFE estimaba, por tanto, que "las repoblaciones forestales habrán de ser objeto de curiosidad y comentario popular" y que los bolsones de procesionaria “( ...) por su visibilidad causarían el deslucimiento de un monumento nacional" 118 .

Con respecto a la gestión forestal de la finca Cuelgamuros la información reciente y actual es sorprendentemente escasa. El monte fue, como tantos otros, consorciado en 1947, lo que significa que a partir de este momento el PFE fue el encar-

117 González Aldama, 1964, 32.

118 FDM, repoblaciones, Madrid, Caja 1741, año 1947. 
gado de la gestión del vuelo y de planificar sus aprovechamientos. Desde entonces la administración forestal ha sido la responsable de todas las intervenciones, primero la central a través de la cuarta División Hidrológica Forestal y del servicio provincial de Madrid y luego la autonómica desde la Consejería de Medio Ambiente. Sin embargo, no se ha encontrado ningún documento técnico sobre su gestión, ni siquiera las bases del consorcio. Sabemos que de forma coetánea al inicio de las repoblaciones (década de los 40) los técnicos del PFE denuncian la entrada de ganado y hay una cierta tensión con los guardas dependientes del Patrimonio Nacional a los que se les acusa de poner en riesgo el éxito de los repoblados ${ }^{119}$.

Como en la mayoría de los montes repoblados en esta etapa, las actuaciones en ellos se han orientado a labores de mantenimiento y mejora, claramente condicionadas por la capacidad presupuestaria. En el 2005 se elabora el Proyecto de Ordenación para el Valle de Cuelgamuros, cuya introducción explicita que "debido al uso social del monte" se debe concebir como un lugar de protección de la biodiversidad de mantenimiento y mejora del paisaje, de protección y de encuentro con la naturaleza" ${ }^{120}$. No debe llevar a engaño esta cita respecto al "uso social del monte", pues a día de hoy no está permitido recorrer el monte libremente, aunque recientemente Patrimonio Nacional se plantea la posibilidad de abrir sendas ${ }^{121}$. En definitiva, la máxima es reducir el carácter monoespecífico de la actual masa dominada por Pinus sylvestris y Pinus pinaster mediante la repoblación de pequeñas manchas con frondosas y aclarar la masa de pino resinero para favorecer la regeneración de otras especies, manteniendo un método de ordenación de monte alto regular con cortas de entresaca de ejemplares maduros, buscando en definitiva una mayor biodiversidad y mejorar el paisaje. "Dada la cantidad de visitantes que recibe" (sic) y sus intereses, se proponen también otras actuaciones escénicas, como la "restauración del Vía crucis" con la limpieza y restauración de las capillas de todo su recorrido, así como introducir "una faja de árboles decorativos (loro, madroño, arces y acebos) a ambos lados de la carretera"122.

Echando la vista atrás, el proceso de repoblación de Cuelgamuros muestra la convergencia de los discursos de los ingenieros de montes con los del régimen franquista, con la suma de argumentos técnicos a los patrióticos y propagandísticos propios del tratamiento de los bosques y la naturaleza en el franquismo. Por otra parte, la inercia en la administración y gestión de las repoblaciones de coníferas propia de las décadas de la segunda mitad del siglo XX -y general en el conjunto del Estado- se pone también en este caso de manifiesto. El intento de aclarar y diversificar la masa arbórea que explicita el Proyecto de Ordenación más reciente (2005) es asi-

119 Archivo General de Palacio (AGP), Administración General, fondo Valle de los Caídos, caja 6.651 .

120 Proyecto de Ordenación del monte M-3168 Valle de Cuelgamuros en San Lorenzo del Escorial de 2005. Dir. Antonio Prieto - Departamento de Economía y gestión Forestal de la ETSIM.

121 Web de Patrimonio Nacional, citada en la nota 72.

122 Proyecto de Ordenación, monte M-3168. Valle de Cuelgamuros, San Lorenzo del Escorial. 2005, p. 284. 
mismo una intención habitual en los documentos técnicos redactados en las dos últimas décadas por las administraciones forestales que inciden sistemáticamente en la importancia de la biodiversidad y el uso social del monte. Parece claro que 75 años después de su inicio el resultado de la repoblación de Cuelgamuros ha sido un éxito técnico y que el valor natural del predio es apreciable, aunque también cabe advertir que las 1.366 ha de la finca se ha contagiado del monumento que alberga, en el sentido de que la inercia en la gestión de algunos de sus elementos, como el tratamiento propuesto para el vía crucis o la prohibición de visitarlo, redunda en el mantenimiento del uso y significado original del monumento.

\section{El Valle de los Caídos, un paisaje político cuestionado}

Nos preguntábamos al inicio sobre el impacto territorial y simbólico de El Valle de los Caídos y sobre la escasa reflexión desde la geografía en el análisis y debate concreto de este conjunto monumental y ahora refrendamos que Cuelgamuros tiene una dimensión territorial ineludible que atañe a la disciplina. No se debe olvidar que, más allá de otros muchos monumentos individuales sobre los que se ha escrito tanto, esto es un conjunto compuesto por una cruz mastodóntica, un cementerio enorme y polémico, un panteón con los restos de un dictador, una basílica que es parte de una abadía benedictina, cuajado todo ello de estatuas y otras obras artísticas y un monte de 1.366 ha, cuyo topónimo se ha transformado: el Valle de los Caídos. La construcción material del paisaje de El Valle de los Caídos se debe entender a partir de la apreciación previa y la construcción de un discurso sobre esos montes, de los que participó el relato oficial sobre la paternidad de la obra y la retórica del franquismo sobre el paisaje, pero que se sustancia en la repoblación forestal del monte Cuelgamuros, con unos criterios científico-técnicos que emanan de la experiencia reforestadora de los ingenieros del PFE. Éste organismo responde a los requerimientos políticos del régimen para ejecutar la reforestación y aunque para ello maneja algunas de las justificaciones habituales de sus proyectos -beneficios productivos e hidrológicos- predomina en este caso la motivación de embellecer el paisaje del Valle de los Caídos. Esa "mejora" de los paisajes vistiendo de verde sus laderas se asume de forma genérica en los textos de muchísimos proyectos de repoblación llevados a cabo por el PFE en toda España, pero se convierte en una razón preeminente en el caso de las repoblaciones "paisajísticas" u "ornamentales" que quieren embellecen, por ejemplo, lugares muy transitados o especialmente significados para el régimen franquista en el entorno de Madrid. Entre las primeras cabe destacar actuaciones en grandes laderas en zonas muy visibles de la Sierra, como telones de fondo, o en los márgenes de los accesos viarios a la ciudad. Entre las segundas, las forestaciones en zonas emblemáticas de la capital, principalmente relacionadas con la reconstrucción de áreas afectadas por la guerra civil o rodeando memoriales vinculados a ésta, como en los casos de El Pardo, la Casa de Campo, Ciudad Universitaria, el Cerro de los Ángeles o el cementerio de Paracuellos del Jarama. Aunque su análisis excede el 
objeto de este trabajo, no cabe duda que se materializa en ellas una parte del discurso paisajístico del PFE.

Para terminar, cabe recordar las contradicciones actuales del territorio de El Valle de los Caídos, que comparte la complejidad de la obra y de su gestión y, sobre todo, comparte su ineludible significado. Por eso, al analizar el territorio de Cuelgamuros, en su sentido material y simbólico, no se puede escapar de la polémica y del necesario posicionamiento frente al monumento, pero también frente al bosque creado a su alrededor. Hoy, que Patrimonio Nacional reivindica los valores naturales y la composición paisajística de este monte, y los técnicos forestales inciden en el uso social del mismo, es imprescindible recordar que es un bosque cerrado al visitante, por el que no se puede pasear, lo que le convierte consecuentemente en un escenario, no en un verdadero paisaje. Desde luego, el monte de Cuelgamuros está sujeto al Valle de los Caídos y su uso condicionado y, en tanto que el monumento no se 'resignifique', no es posible que abandone la condición de escenario político y se convierta en un paisaje apreciable colectivamente.

\section{Siglas utilizadas}

AGA

AGP

AGPM

ARCM

BNE

FDM

ICONA

PFE
Archivo General de la Administración

Archivo General de Palacio

Archivo General de Protocolos de Madrid

Archivo Regional de la Comunidad de Madrid

Biblioteca Nacional Española

Fondo Documental del Monte

Instituto Nacional para la Conservación de la Naturaleza

Patrimonio Forestal del Estado

\section{Bibliografía}

AGNOLETTI, Mauro. Bosques e industria de la madera en Italia, de la unificación al fascismo (1861-1940). In SEBASTIÁN AMARILLA, José Antonio \& URIARTE AYO, Rafael. Historia y economia del bosque en la Europa del sur (siglos XVIII-XX). Zaragoza: Prensas Universitarias de Zaragoza. 2003, p. 403-430.

AGUILAR FERNÁNDEZ, Paloma. Los lugares de memoria de la guerra civil. El Valle de los Caídos: la ambigüedad calculada. In TUSELL, Javier. El régimen de Franco (1936-1975). Politica y relaciones exteriores. Madrid: Universidad Nacional de Educación a Distancia. 1993, pp. 485-498.

AGUILAR FERNÁNDEZ, Paloma. Memoria y olvido de la guerra civil española. Madrid: Alianza editorial. 1996, 435 p.

ARAQUE JIMÉNEZ, Eduardo \& SÁNCHEZ MARTÍNEZ, José Domingo. Repoblación forestal en Andalucía: intervenciones históricas y situación actual. Jaén: Universidad de Jaén, 2009, 365 p.

ARBOLÍ HIDALGO, José María. El arbolado en las carreteras de la provincia de Alicante. Montes. Publicación de los Ingenieros de Montes. 1958, nº 84, p. 491-494. 
ARMIERO, Marco. A Rugged Nation. Mountains and the Making of Modern Italy, Cambridge: The White Horse Press. 2011, 228 p.

ARMIERO, Marco \& GRAF VON HARDENBERG, Wilko. Green rethoric in Blackshirts. Italian fascist and the environment. Environment and History. 2013, vol. 19, 283311

ATKINSON, David \& COSGROVE, Denis. Urban Rhetoric and Embodied Identities: City, Nation, and Empire at the Vittorio Emanuele II Monument in Rome, 18701945. Annals of the Association of American Geographers. 1998, Vol. 88( 1), p. 28-49

BRAIN, Stephen. The great Stalin plan for the transformation of Nature. Environmental History. 2000, vol. 15(4), p. 670-700.

BONET CORREA, Antonio. El crepúsculo de los Dioses. In BONET CORREA, Arte del franquismo. Madrid: Cátedra. 1981, pp. 315-331.

BOX VARELA, Zira. La fundación de un régimen. La construcción simbólica del franquismo. Madrid: Universidad Complutense de Madrid. Tesis doctoral. 2008, $479 \mathrm{p}$.

BOX VARELA, Zira. Paisaje y nacionalismo en el primer franquismo. Hispanic Research Journal. 2016, vol. 17(2), p. 123-140.

BRUGGERMEIER, Franz-Josef; CIOC, Mark \& ZELLER, Thomas. How green were the Nazis? Nature, Environment and Nation in the Third Reich. Athens: Ohio University Press. 2005, 283 p.

CANOSA-BETÉS, Jorge. El Valle de los Caídos. Revisando la proyección en el paisaje del mayor monumento del franquismo. In IX Jornadas de Jóvenes en Investigación Arqueológica, Santander. 2016.

CHAPOUTOT, Johann. Les nazis et la «nature»: Protection ou prédation? Vingtième Siècle. Revue d'histoire. 2012, Vol, 113(1), p. 29-39.

CIRICI, Alexandre. La estética del franquismo. Barcelona: Editorial Gustavo Gili. 1977, $191 \mathrm{p}$.

FERNÁNDEZ DELGADO, Javier et al. La memoria impuesta: estudio y catálogo de los monumentos conmemorativos de Madrid: 1939-1980. Madrid: Ayuntamiento, Delegación de Cultura. 1982, 446 p.

FERRANDIZ, Francisco. Guerras sin fin guía para descifrar el Valle de los Caídos en la España contemporánea. Politica y Sociedad. 2011 Vol. 48 (3), p. 481-500.

FOOTE, Kenneth E.y AZARYAHU, Maoz. Toward a geography of memory. Geographical dimensions of public memory. Journal of Political and Military Sociology. 2007, 35 (1), p. 125-144

FOREST, Benjamin \& JOHNSON, Juliet. Unraveling the Threads of History. SovietEra Monuments. Annals of the Association of American Geographers. 2002, Vol. 92 (3), p. 524-547.

FOREST, Benjamin; JOHNSON, Juliet \& TILL, Karen. Post-totalitarian national identity. Public memory in Germany and Russia. Social \& Cultural Geography. 2004, Vol. 5(3), p. 357-380. 
FOXALL, Andrew. A contested landscape: Monuments, public memory, and post -Soviet identity in Stavropol', Russia. Communist and Post-Communist Studies. 2013, vol. 46, p. 167-178.

GARCÍA ÁLVAREZ, Jacobo. Territorio y nacionalismo. La construcción geográfica de la identidad gallega. Santiago de Compostela: Xunta de Galicia. 2003, 181 p.

GARCÍA ÁLVAREZ, Jacobo. Lugares, paisajes y políticas de la memoria. Boletín de la Asociación de Geógrafos Españoles, 2009, nº 51, p. 175-202.

GARCÍA ÁLVAREZ, Jacobo. Paisaje, memoria histórica e identidad nacional en los inicios de la política de conservación de la naturaleza en España: de Covadonga a San Juan de la Peña. Hispania. 2013, nº 244, p. 409-438.

GARCÍA CARBALLO, Ángela. Los paisajes residenciales exclusivos de Madrid: la segregación de las élites y la alta sociedad madrileñas. Madrid: Universidad Autónoma de Madrid - Tesis doctoral. 2012, 688 p.

GARCÍA-ESCUDERO Y FERNÁNDEZ URRUTIA, Pío. Creación de un Parque en los terrenos de la Ciudad Universitaria, Revista nacional de educación. 1941, nº 11, p. 100-104.

GARCÍA-ESCUDERO Y FERNÁNDEZ URRUTIA, Pío. Las masas forestales en el paisaje. Montes. Publicación de los Ingenieros de Montes. 1956, nº 70, p. 233-240

GÓMEZ DE LA SERNA, Gaspar. Castilla La Nueva. Barcelona: ed. Destino. 1964, 596 p.

GÓMEZ MENDOZA, Josefina. Ciencia y politica de los montes españoles. Madrid: ICONA, 1992, $260 \mathrm{p}$.

GOMEZ MENDOZA, Josefina. Paisajes forestales e ingeniería de montes. In ZOIDO, Florencio. Paisaje y Ordenación Del Territorio. Sevilla: Junta de AndalucíaFundación Duques de Soria. 2002, p. 237-254.

GOMEZ MENDOZA, Josefina. Del patrimonio paisaje a los paisajes patrimonio. Documents d'Anàlisi Geogràfica. 2013, no 59, p. 5-20.

GÓMEZ MENDOZA, Josefina \& MATA OLMO, Rafael. Actuaciones forestales públicos desde 1940. Objetivos, criterios y resultados. Agricultura y Sociedad. 1992, no 65, p. 15-64.

GONZÁLEZ ALDAMA, Antonio. El PFE en el Valle de los caídos. Boletín Informativo del Patrimonio Forestal del Estado. 1964, n 2, p. 30-33.

HARVEY, David. Monument and Myth. Annals of the Association of American Geographers. 1979, Vol. 69 (3), p. 362- 381.

HEPWORTH, Andrea. Site of memory and dismemory: the Valley of the Fallen in Spain. Journal of Genocide Research. 2014, Vol. 16 (4), p. 463-485.

HERMOSO CUESTA, Miguel. El monasterio de El Escorial y el franquismo. In MORENO MARTIN, Francisco J. El franquismo y la apropiación del pasado. Madrid: Editorial Pablo Iglesias. 2017, p. 271-306.

HITE, Katherine. Politica y arte de la conmemoración. Memoriales América Latina y España. Santiago de Chile: Mandrágora. 2013, 187 p.

HOBSBAWM, Eric \& RANGER, Terence. The Invention of Tradition. Cambridge: Cambridge University Press. 1983, 320 p. 
HOBSBAWM, Eric. Foreword. In ADES, D. Et al. Art and Power: Europe Under the Dictators 1930-45, London: Thames and Hudson. 1995, p.11-15.

IGNATIEFF, Michael. Soviet War Memorials. History Workshop. 1984, vol. 17, p. $157-$ 163.

IMORT, Michael. "Eternal Forest-Eternal Volk" The Rhetoric and Reality of National Socialist Forest Policy. In BRUGGERMEIER, Franz-Josef; CIOC, Mark \& ZELLER, Thomas. How green were the Nazis? Nature, Environment and Nation in the Third Reich. Athens: Ohio University Press. 2005, p. 43-72

IMORT, Michael. A sylvan people. Wilhelmine forestry and the forest as a symbol of germandon. In LEKAN, Thomas \& ZELLER, Thomas. Cultural landscapes and environmental History. New Brunswick-NewJersey: Rutgers University Press. 2005, p. 55-80.

JELIN, Elizabeth \& LANGLAND, Victoria. Monumentos, memoriales y marcas territoriales. Madrid: Siglo XXI. 2003, 229 p.

JIMÉNEZ ZAYOS, C. Presencia del PFE en la nueva paisajística de Despeñaperros. Boletín Informativo del Patrimonio Forestal del Estado, 1964, n²2, p. 48-53.

JOHNSON, Nuala. Cast in Stone. Monuments, Geography, and Nationalism, Environment and Planning, Society and Space. 1995, n 13, p. 51-65.

LLORENTE HERNÁNDEZ, Ángel. Arte e ideología en la España de la Postguerra (19391951). Madrid: Editorial de la Universidad Complutense de Madrid - Tesis Doctoral. 1992, 2004 p.

LÓPEZ-CADENAS DE LLANO, Filiberto. El paisaje y la carretera. Montes. Publicación de los Ingenieros de Montes. 1966, n 130, p. 323-329.

LORENTE SOROLLA, Joaquín. Las repoblaciones ornamentales en la estética del paisaje. Montes. Publicación de los Ingenieros de Montes. 1960. n 93, p. 266-270

LUZÓN GARCÍA, Ana. La presencia histórica del fuego en los reales bosques de El Escorial. Documentos de su archivo municipal. In MONTIEL MOLINA, Cristina. La presencia histórica del fuego en el territorio. 2013, p. 137-154.

MADRAZO GARCÍA DE LOMANA, Gonzalo. La evolución de los paisajes forestales en la vertiente segoviana de la Sierra de Guadarrama. Valladolid: Junta de Castilla y León. 2010, 448 p.

MADRAZO GARCÍA DE LOMANA, Gonzalo; LACASTA REOYO, pilar \& SAEZ POMBO, Ester. El Escorial: conformación y reconocimiento de un Real Sitio como paisaje patrimonial. In MOLINERO HERNADO et al. Paisajes patrimoniales de España. Madrid: Ministerio de Agricultura, Pesca, Alimentación y Medio Ambiente. 2017, T. II, p. 1240-1263.

MAS HERNÁNDEZ, Rafael. El Territorio. In MARTÍNEZ DE PISÓN, Eduardo. Madridy la Sierra de Guadarrama. Madrid: Ayuntamiento de Madrid. 1998, p. 37-77.

MAYO, James M. War Memorials as Political Memory. The Geographical Review. 1988, vol. 78 ( 1), p. 62-75

MCNEILL, John R. Something new under the sun. An environmental history of the twentieth century. London: Penguin Books. 2000, 416 p. 
MÉNDEZ, Diego. El Valle de los Caídos: idea, proyecto y construcción. Madrid: Fundación Nacional Francisco Franco. 1982, 351 p.

MÉNDEZ GUTIÉRREZ DEL VALLE, Ricardo. La expansión del Noroeste del Área Metropolitana. In FERNÁNDEZ GARCÍA, Antonio. Madrid: de la prehistoria a la Comunidad Autónoma. Madrid: CAM-Consejería de Educación. 2008, p. 667-693.

MINISTERIO DE LA PRESIDENCIA. Informe de la comisión de expertos sobre el futuro del Valle de los Caídos. Madrid: Ministerio de la Presidencia. 201 1, 30 p.

MUÑOZ JIMÉNEZ. Julio. Los despoblados en el paisaje de las Tierras Altas de Yanguas y de San Pedro (Soria): pueblos desocupados, pueblos abandonados y pueblos en ruinas. Ería. 2016, no 99, p. 131-154.

NOGUÉ I FONT, Joan. Nacionalismo, territorio y paisaje en Cataluña. In ORTEGA CANTERO, Nicolás. Paisaje, memoria histórica e identidad nacional. Madrid: Universidad Autónoma de Madrid-Fundación Duques de Soria. 2005, p. 146169.

NOGUÉ I FONT, Joan. La génesis y la evolución de la valoración moderna del paisaje en Cataluña. Cuadernos Geográficos. 2016, Vol. 55(2), p. 28-45

NORA, Pierre. Les Lieux de mémoire (La République, La Nation, Les France). París: Gallimard. 1997, 3 t.

NORA, Pierre. Between Memory and History: Les Lieux de Mémoire. Representations. $1989, \mathrm{n}^{\circ} 26$, p. 7-24.

ORTEGA CANTERO, Nicolás. Paisaje, memoria histórica e identidad nacional. Madrid: Universidad Autónoma de Madrid-Fundación Duques de Soria. 2005, p. 294.

ORTEGA CANTERO, Nicolás. La valoración patrimonial y simbólica del paisaje de Castilla (1875-1936). Ería. 2007, nº. 73-74, p. 137-159.

ORTEGA CANTERO, Nicolás \& GARCÍA ÁLVAREZ, Jacobo. Paisaje y lugares de memoria: Covadonga y El Paular. In MARTÍNEZ DE PISÓN, Eduardo; ORTEGA CANTERO, Nicolás. Los valores del paisaje. Madrid: Ediciones de la Universidad Autónoma de Madrid / Fundación Duques de Soria. 2009, p.45-93.

OSBORNE, Brian S. Constructing landscapes of power: the George Etienne Cartier monument, Montreal. Journal of Historical Geography. 1998, vol. 24 (4), p. 431458.

PATRIMONIO NACIONAL. Monumento Nacional de Santa Cruz de Valle de los Caídos: (guía turística). Madrid: Patrimonio Nacional. 1959, 64 p.

PÉREZ DE ÚRBEL, Justo. El Monumento de Santa Cruz del Valle de los Caídos. Madrid: Instituto de Estudios Madrileños. 1959, 38 p.

PROST, Antoine. Les monuments aux morts. Culte républicain ? Culte civique ? Culte patriotique? In NORA, Pierre. Les Lieux de mémoire (La République, La Nation, Les France). París: Gallimard. 1984-1992, Vol. 1, p. 199-223.

QUEVEDO, José. Historia del Real Monasterio de San Lorenzo, llamado comúnmente del Escorial, desde su origen y fundación hasta fin del año de 1848. Madrid: establecimiento tipográfico Mellado. 1849.381 p. 
REVUELTA SALINAS, Antonio. Repoblaciones paisajísticas en carreteras principales. Montes. Publicación de los Ingenieros de Montes. 1967, nº 137, p. 361-363.

RICO BOQUETE, Eduardo. Las repoblaciones del Patrimonio Forestal del Estado y del ICONA en la provincia de Badajoz, 1941-1977. Historia Agraria. 2008, nº 46, p. $91-124$.

RICO BOQUETE, Eduardo. Repoblación forestal y sustitución de especies en los montes de utilidad pública de la provincia de Soria, 1940-1975. Ager. 2008, nº 7 , p. 77-108.

RICO BOQUETE, Eduardo. La actividad repobladora del Patrimonio Forestal del Estado en los años del "desarrollismo": un estudio sobre dos montes de Guadalajara (1959-1975). Estudios Rurales. 2016, Vol. 6 (11), p. 70-93.

RUEDA LAFFOND, José Carlos \& MORENO GARRIDO, Belén. Viejos espacios de memoria y nuevos discursos televisivos: El Valle de los Caídos. Investigaciones históricas: Época moderna y contemporánea. 2013, no 33, p. 235-260.

SÁEZ POMBO, Ester. Montes públicos, territorio y evolución del paisaje en la Sierra Norte de Madrid. Madrid: Consejería de Medio Ambiente. 2000, 245 p.

SÁEZ POMBO, Ester \& MADRAZO GARCÍA DE LOMANA, Gonzalo. La Sierra de Guadarrama. Una Montaña transformada por el ser humano. Revista Ambienta, 2013, no 103, p. 68-89.

SÁNCHEZ MECO, Gregorio. El Escorial: de comunidad de aldea a villa de realengo. El Escorial: Ayuntamiento de El Escorial-Concejalía de Cultura. 1995, 721 p.

SCHAMA, Simon. Landscape and Memory. New York: Alfred A. Knopf. 1995, 652 p.

SIDOROV, Dmitri. National Monumentalization and the Politics of Scale: The Resurrections of the Cathedral of Christ the Savior in Moscow. Annals of the Association of American Geographers. 2000, Vol. 90(3), p. 548-572.

SIGÜENZA, José de. La fundación del monasterio de El Escorial. Madrid: Aguilar. [1605] 1963, $471 \mathrm{p}$.

SOLÉ I BARJAU, Queralt. Inhumados en el Valle de los Caídos. Los primeros traslados desde la provincia de Madrid. Hispania Nova. Revista de Historia Contemporánea. 2009, no 9, p. 219-249.

SORENSEN, Marie Louise S. \& VIEJO-ROSE, Dacia. War and cultural heritage. Biographies of Place. Cambridge: Cambridge University Press. 2015, 311 p.

STANGL, Paul. The Soviet War Memorial in Treptow, Berlin. The geographical review. 2003, Vol. 93(2), p. 213-236.

STOCKEY, Gareth. Valley of the Fallen. The (n)ever changing face of General Franco's monument. Nottingham: Critical, Cultural and Communications Press. 2013, 109 p.

SUEIRO, Daniel. La verdadera historia del valle de los caídos. Madrid: Sedmay ediciones. 1976, 286 p.

TILL, Karen E. Staging the past: landscape designs, cultural identity and erinnerungspolitik at at Berlin,s neue wache. Ecumene. 1999, Vol. 6 (3), p. 251-283. 
TORT I DONADA, Joan. Cuatro escritores (Verdaguer, Ruyra, Pla y Manent) en la conformación del 'canon paisajístico' catalán. Ería. 2007, n 73-74, p. 351-372.

URIARTE AYO, Rafael. Repoblaciones, paisaje forestal y desarrollo industrial en el País Vasco atlántico (1940-1975). Historia agraria, 2010, nº 51, p. 109-142.

VALENZUELA RUBIO, Manuel. El Escorial. De Real Sitio a Núcleo turístico-residencial. Anales del Instituto de Estudios Madrileños. 1974, nº. 10, p. 363-402.

VALENZUELA RUBIO, Manuel. Urbanización y crisis rural en la Sierra de Madrid. Madrid: Instituto de Estudios de Administración Local, 1977, 534 p.

VALENZUELA RUBIO, Manuel. El Guadarrama de los noventa o lo metropolitano como riesgo. In SÁEZ DE MIERA, Antonio. La Sierra de Guadarrama. Naturaleza, paisaje y aire de Madrid. Madrid. Agencia de Medio Ambiente de la Comunidad de Madrid. 1992.

WOLSCHKE-BULMAHN, Joachim. Nature and Ideology Natural Garden Design in the Twentieth Century, Washington D.C.: Dumbarton Oaks Research Library and Collection. 1997, $284 \mathrm{p}$.

XIMÉNEZ DE EMBÚN Y GONZÁLEZ-ARNAO, Joaquín. Sobre estética forestal y Parques Nacionales. El bello monte valldemosino y la técnica. Montes. Publicación de los Ingenieros de Montes. 1948, $\mathrm{n}^{\circ}$ 22, p. 305-312.

๑ Copyright: Gonzalo Madrazo García de Lomana; Ester Sáez Pombo, 2018

(c) Copyright: Scripta Nova, 2018.

Ficha bibliográfica:

MADRAZO GARCÍA DE LOMANA, Gonzalo; SÁEZ POMBO, Ester. Escenarios de la memoria y el poder. La construcción del paisaje de El Valle de Los Caídos, Scripta Nova. Revista Electrónica de Geografía y Ciencias Sociales. Barcelona: Universidad de Barcelona, 15 de octubre de 2018, vol. XXII, nº 600. [ISSN: 1138-9788] 